\title{
Fixed-Term Work Contracts and Anti-Immigration Attitudes. A Novel Test of Ethnic Competition Theory*
}

\author{
Evelyn Ersanilli ${ }^{1}$ and Patrick Präg ${ }^{2}$ \\ ${ }^{1}$ Department of Political Science, University of Amsterdam \\ ${ }^{2}$ CREST, ENSAE, Institut Polytechnique de Paris
}

December 14, 2021

\begin{abstract}
Whether labor market competition is shaping anti-immigration attitudes is a contentious issue. We conduct a novel test of ethnic competition theory by comparing the attitudes towards immigration of workers with fixed-term contracts to those with permanent jobs in Europe. Fixed-term contract workers are particularly at risk of competition as they have to compete for jobs in the foreseeable future. In the first step of our investigation, we analyze cross-sectional data (ESS, 2002-18) from 18 Western European countries. We find
\end{abstract}

${ }^{*}$ This study is forthcoming at Socio-Economic Review, doi: 10.1093/ser/mwab059. Previous versions were presented at the ECSR conference in Milan in 2017 as well as Nuffield College and VU University Amsterdam. We thank discussants at these occasions as well as the three anonymous reviewers.

Evelyn Ersanilli's work is supported by the European Research Council (ERC-2017-StG760043, 'RIGHTS'). Patrick Präg's work is supported by the French National Research Agency ANR, 'Investissements d'Avenir' (LabEx Ecodec/ANR-11-LABX-0047).

The data used for our analysis are publicly available (ESS, 2002, 2004, 2006, 2008, 2010, 2012, 2014, 2016, 2018; Schupp et al., 2017). We provide a set of Stata do-files for replicating our analyses on-line (Ersanilli and Präg, 2021). 
that - contrary to our expectation - fixed-term workers are less antiimmigration. The effect is substantively small. In the second step, we use a fixed-effects design with longitudinal data from the German Socio-Economic Panel (GSOEP, 1999-2015) to rule out time-constant unobserved heterogeneity. We find that transitioning from a fixedto a permanent contract does not affect anti-immigration attitudes. Our combined results thus add to the growing body of studies that do not find evidence for labor market competition as an explanation of anti-immigrant attitudes.

\section{Introduction}

As immigration takes a prominent position in public debates in many countries, understanding of the drivers of attitudes towards immigration is crucial. Group threat theory (Blalock, 1967) is one of the most prominent approaches to explaining anti-immigration attitudes. Its main claim is that competition with migrants over material or symbolic resources leads to a sense of ethnic threat, which in turn results in anti-immigration attitudes. Competition in the labor market is the focal point of studies using ethnic competition theory. Whether these studies provide convincing support for ethnic competition theory is highly contested (e.g. Hainmueller and Hopkins, 2014). We contribute to this debate by exploring the role of fixed-term contracts in shaping anti-immigration attitudes.

A large body of studies on ethnic competition theory looks at the effect of education. The assumption is that migrants are competitors for labor market participants with a similar-generally low-level of education (Cavaille and Marshall, 2019; Dancygier and Donnelly, 2013; Margaryan et al., 2019; Polavieja, 2016; Scheepers et al., 2002; Schneider, 2008). This approach has been criticized, as education is related to liberal attitudes across the board, which makes it difficult to tease out any effect on competition (e.g. Hainmueller and Hopkins, 2014; Hello et al., 2006; Pecoraro and Ruedin, 2016). Furthermore, education is a coarse measure of job skills. People may have received training on the job or have skills not directly related to educational level that influence the likelihood that their jobs could be taken up by im- 
migrants. Moreover, cross-sectional studies looking at education tend to ignore that while immigrants in many countries are overrepresented in lowskilled work they are also commonly employed at intermediate and higher levels (Pecoraro and Ruedin, 2016). More sophisticated measures of competition such as occupation level, skill specificity and communication intensity of jobs, or sectoral dynamics generally show support for the role of competition, though in some cases only for those with higher education or at the group rather than the individual level (Dancygier and Donnelly, 2013; Ortega and Polavieja, 2012; Pardos-Prado and Xena, 2019).

As several authors have pointed out, competition is not only determined by the number of immigrants and their skill level, but depends on the availability of jobs at these skill levels. Research looking the relation between occupational unemployment or sectoral growth and anti-immigrant attitudes found ambiguous support for the role of ethnic competition (Dancygier and Donnelly, 2013; Pardos-Prado and Xena, 2019; Pecoraro and Ruedin, 2016).

In European labor markets, workers tend to be sheltered from competition by legal constraints on wage cuts and employment termination. This limits the competition faced by people in employment - even if immigrants have the skills to perform their job and job availability is low. Yet not all workers are sheltered to the same extent. Insecure forms of employment such as fixed-term, involuntary part-time, and zero-hour contracts are becoming more prevalent in European labor markets (European Parliament, 2016). Their marginal labor market position leaves such workers more exposed to competition. This makes them a good test case for ethnic competition theory. Moreover, as new labor market insecurities show a substantial, albeit varying, presence across sectors and education groups (European Parliament, 2016; Polavieja, 2005), they allow disentangling the effects of labor market competition from those that shape general liberal attitudes.

In this study, we will focus on the effect of fixed-term contracts. In the member states of the European Union, the share of fixed-term contracts has sharply increased, from about 8.6 per cent in 1985 to a peak of 14.3 per cent in 2017 (OECD, 2020b). Over the same period, this rate among 15-24 year-olds went from 22.3 per cent to 44.2 per cent. Given a certain skill level, fixed-term contracts make workers more vulnerable to competition with immigrants- 
either over a renewed contract for their current employment or over new employment at the end of their contract - than their colleagues with permanent contracts. We argue that, knowing that their contract ends at a fixed point in the near future, fixed-term contract workers experience what Pardos-Prado and Xena (2019, p. 289) call 'prospective competition.' Following ethnic competition theory, this sense of prospective competition should lead to stronger anti-immigration attitudes.

We build on previous studies by examining three sets of factors that may influence whether workers on fixed-term contracts will experience more prospective labor market competition with migrants than workers on permanent contracts. Firstly, competition may depend on whether migrants can be hired for the position of the native fixed-term contract worker. We use sectoral share of immigrant workers as a proxy for replaceability and examine its moderating role on the relationship between fixed-term contracts and anti-immigration attitudes. Secondly, the level of competition depends on the availability of jobs. We therefore examine the moderating role of sectoral level unemployment. Thirdly, the extent to which fixed-term contracts expose people to more competition may depend on the degree of insider-outsider segmentation in the labour market. This segmentation is driven by the level of employment protection of fixed-term vs. permanent contracts (Polavieja, 2003; Passaretta and Wolbers, 2019). If dismissal protection for permanent contracts is low, fixed-term contracts are only marginally less secure than permanent ones and are unlikely to increase competition (Marx and Picot, 2020). To examine this, we check if the gap between employment protection legislation (EPL) for permanent and fixed-term contracts moderates the relationship between fixed-term contracts and anti-immigration attitudes.

Our analyses proceeds in two steps. First, we use nine rounds of the European Social Survey (ESS, 2002-18), comparing anti-immigration attitudes of fixed-term workers to those of workers with permanent contracts across 18 Western European countries to ensure the external validity of our findings. We focus on Western Europe due to the strong geographic division in antiimmigrant attitudes between East and West Europe (Czaika and Di Lillo, 2018; Heath and Richards, 2020, 2019). In a second step, we make use of longitudinal data from the German Socio-Economic Panel (GSOEP, 1999- 
2015) in a fixed-effects design to ensure the internal validity of our findings. This analysis also meets calls to take a dynamic rather than static approach to competition (Lancee and Pardos-Prado, 2013; Meuleman et al., 2009).

To preview our findings, we do not find a substantive difference in antiimmigration attitudes between fixed-term workers and permanent employees. This finding holds across education level, social class, countries, employment protection gap, and sectoral immigrant and unemployment levels. We thus add to the growing doubts on the merits of ethnic competition theory as applied to economic competition.

\section{Background and hypotheses}

\section{Labor market competition and anti-immigrant attitudes}

What makes individuals like or dislike immigrants? Group conflict theory is one of the most prominent explanations used for understanding the attitudes held about immigrants and immigration. Ethnic competition theory is based on a synthesis of group conflict theory and social identity theory. Social identity theory holds that people have a need to belong to a high-status group. To fulfill this need, they will assign negative characteristics to any out-group, identify with their in-group, and see their in-group as being better than the out-group. This happens regardless of competition over resources. Scheepers et al. (2002) argue that group competition intensifies the process described by social identity theory. Group conflict theory posits that competition over resources leads to a sense of threat which in turn leads to ethnic exclusionism such as opposition to immigration (Blalock, 1967; Olzak, 1992; Scheepers et al., 2002). Competition can take place over economic resources, such as jobs, or symbolic resources such as national identity or language. We focus our discussion here on competition over economic resources.

Competition can occur at the macro- as well as at the micro-level. At the macro-level, fewer resources or more people competing over them will increase competition, e.g. the arrival of immigrants, an economic downturn, or the combination of the two. At the micro-level, people who hold labor market positions similar to those taken up by immigrants experience greater 
competition (Scheepers et al., 2002).

Ethnic exclusionism can be driven by actual or perceived competition. People's perception of competition - also known as 'perceived threat' - may act as a mediator between actual competition and anti-immigration attitudes (Billiet et al., 2014; Scheepers et al., 2002). Conversely, perceived threat might be a proxy for general prejudice rather than a result of actual competition (Hainmueller and Hopkins, 2014; Polavieja, 2016).

The relation between competition and exclusionism can be based on economic self-interest or group interest. People in positions similar to those often taken up by migrants - e.g. working class, low educated - may display more negative attitudes about immigrants because immigrants pose a threat to their personal economic interests, such as job security or wage development (Billiet et al., 2014; Bobo, 1988; McLaren, 2003; Polavieja, 2016; Scheve and Slaughter, 2001; Scheepers et al., 2002). Alternatively, people in positions similar to those of migrants may develop more negative attitudes to immigration out of concern for the interests of their group, so-called 'sociotropic' concerns (Hainmueller and Hopkins, 2014; McLaren, 2003). Following this argument, people in positions similar to those of migrants are more negative about immigration, because their position provides them with more information about the presence of an immigrant threat (Dancygier and Donnelly, 2013; Tolsma et al., 2007), or because they identify with the group of people that is most affected by the threat (e.g. Citrin et al., 1997; Dancygier and Donnelly, 2013; Scheepers et al., 2002) — not because they are personally more threatened.

\section{Previous research}

The proposition that people most exposed to competition with immigrants show stronger ethnic exclusion and anti-immigration attitudes has been studied extensively (Citrin et al., 1997; Dancygier and Donnelly, 2013; Hainmueller et al., 2015; Helbling and Kriesi, 2014; Scheepers et al., 2002). The most used indicator of exposure to competition is education. Lower-educated report more ethnic threat and harbor stronger anti-immigration attitudes than their higher-educated counterparts (see e.g. Billiet et al., 2014; Cavaille 
and Marshall, 2019; Dancygier and Donnelly, 2013; Polavieja, 2016; Scheepers et al., 2002). This has been interpreted as support for ethnic competition theory, as low-skilled people face most competition from immigrants who- at least in the United States and in most European countries - tend to be lowskilled. However, ethnic competition is not the only possible explanation for educational differences in anti-immigrant attitudes. Firstly, education does not only indicate skills for the labor market, it also reflects general attitudes towards issues such as diversity and ethnocentrism (Hainmueller and Hopkins, 2014; Pecoraro and Ruedin, 2016). Secondly, education is a coarse and indirect measure of skill (Ortega and Polavieja, 2012; Pardos-Prado and Xena, 2019; Polavieja, 2016), thus giving limited insights into economic competition.

Survey experiments allow randomizing characteristics of immigrants such as education or skill-level to elicit anti-immigration attitudes in a causal fashion. They can thus tease out the influence of the factor of interest from associated factors. Hainmueller and Hiscox (2010) asked half of their respondents about their views on low-skilled migrants coming to the US and the other half about high-skilled migrants. They find no evidence of economic self-interest shaping attitudes: both lower and higher educated respondents are equally opposed to low-skilled immigration and less opposed to highskilled than low-skilled immigration. In a subsequent survey experiment, Hainmueller and Hopkins (2015) show that labor market position and education vary little with immigration preferences. Related survey experiments in Switzerland (Helbling and Kriesi, 2014) and fifteen European countries (Naumann et al., 2018) yielded similar results. The authors of these studies interpret their findings as evidence against ethnic competition theory. However, as their cross-sectional counterparts, these studies can be criticized for using a coarse measure of skill and thus of competition. Malhotra et al. (2013) conducted an experiment where they varied scenarios about a specific skill-set (high technology). They find respondents are more opposed to immigration of people with a similar skill set, thus supporting the role of economic self-interest, though with a small effect size.

A non-experimental approach related to Malhotra et al. (2013) exploits variation in competition across segments of the labor market such as sectors 
and occupation groups. An inflow of immigrants into an industry creates ethnic competition, unless the sector is expanding. Dancygier and Donnelly (2013) analyze the effect of job growth and immigrant inflow at the sectoral level. Sectoral growth has a negative relation with anti-immigration attitudes. Sectoral immigrant inflow is unrelated to anti-immigration sentiments during times of economic growth, but it increases anti-immigration attitudes when economies are declining or perceived to be declining. This pattern holds for higher- and lower- educated workers in the same way, even though they supposedly differ in the extent to which they would personally face competition from immigrant inflows. This goes against expectations based on self-interest. Dancygier and Donnelly (2013) interpret their findings as support for group-interest based expectations, with people's perception of group competition shaped by their sectoral experience.

Using both cross-sectional and panel data, Pardos-Prado and Xena (2019) find a negative effect of the occupational unemployment rate on attitudes towards immigrants. As the occupational unemployment rate has but a very weak relation with national economic satisfaction, they interpret their finding as support for the self-interest rather than the group interest explanation; people in occupations with higher unemployment are more anti-immigration because they are concerned about their personal employment chances, not about the economy as a whole. In their study on Swiss workers, however, Pecoraro and Ruedin (2020) find that the effect of occupational unemployment becomes insignificant when accounting for sorting of less-productive workers into jobs with high shares of immigrants.

Another group of studies focusing on personal interest explanations of economic competition and anti-immigration attitudes examines the role of job skills. Over and above education, Ortega and Polavieja (2012) took into account the time it would take to learn a specific job, given the required job-specific human capital - and the degree of manual vs. communicational intensity of a position. Workers in occupations that require more specific human capital and more communication - in jobs that presumably can less easily be taken up by immigrants - are less opposed to immigration, also after accounting for level of education. Pardos-Prado and Xena (2019) define skill specialization as occupational group segmentation and show that people 
with higher levels of skill-specificity are more negative about immigration. They argue this is because people in highly specialized occupations will find it more difficult to find new employment (lower job availability) and are thus more concerned with newcomers in the labor market. Even though the two studies find contradictory effects of skill specialization, both purport to support the personal interest path of ethnic competition theory. An alternative explanation of their findings could be the role of 'work logic.' Occupations that require more interactions with other people may for example lead their holders to have more liberal attitudes, including towards immigration (Güveli et al., 2007; Oesch, 2012; Van de Werfhorst and de Graaf, 2004).

Unemployment is a more direct measure of personal competition. Unemployed people are personally confronted with competition in their attempts to re-enter the labor market. Findings on the relation between unemployment and ethnic exclusionism are contradictory; some studies supporting that unemployed people perceive more ethnic threat and are more anti-immigrant than those in employment (Billiet et al., 2014; Scheepers et al., 2002; Schneider, 2008; Van Setten et al., 2017), and others finding no such relation (Citrin et al., 1997; Kuntz et al., 2017; O'Rourke and Sinnott, 2006). Pecoraro and Ruedin (2016) find that among Swiss workers a higher self-assessed risk of unemployment is related to negative views of migrants, but only if they have tertiary education or are employed in jobs demanding high skills. Heizmann (2015) found that unemployment has a stronger negative relation with perceived labor market competition when policies make it more difficult to re-enter the labor market, specifically when there is stronger employment protection legislation. Using German panel data and a fixed-effects approach, Lancee and Pardos-Prado (2013) show that becoming unemployed leads to more concern about immigration. These findings are in line with ethnic competition theory, particularly with a self-interest interpretation.

In sum, the call is still out on labor market competition theory. There is no consensus as to how competition should best be conceived. Comparisons of educational groups only give a very broad impression of differences in labor market competition, both comparison of education groups and skills can be confounded by unobserved factors, survey experiments hinge on the assumption that reactions to hypothetical scenarios are similar to real-world 
reactions, and it remains uncertain whether the relations found are based on personal or group interest.

\section{Fixed-term contracts and competition}

According to OECD data for 2019, 13.6 per cent of employees in the EU-28 are on a temporary contract. Among 24-54 year-old employees, 11.6 per cent have a temporary contract, up from 9.4 per cent in 2000 (OECD, 2020b). This average hides considerable variation; ranging from a share below three per cent in the Baltic States and Romania to over 25 per cent in Spain. Fixedterm contracts have long-term negative impacts on wages (Pavlopoulos, 2013; Yoon and Chung, 2016). Contract type also shapes attitudes; people on fixedterm contracts are more in favor of income redistribution and political parties that support these policies (Marx and Picot, 2013; Marx, 2014; Vlandas, 2020) — preferences in line with their self-interest.

In the labor market, fixed-term contracts increase exposure to competition. To replace workers on permanent contracts, employers need to fire them. This is generally a costly procedure. Fixed-term workers however can be let go at the end of their contract term at low or no costs to the employer. Workers on fixed-term contracts indeed perceive their jobs as less secure than those on permanent contracts (Erlinghagen, 2008). Knowing that at the end of their contract, they will need to compete to stay in their current position and if this fails, to find new employment, workers on fixed-term contracts, experience prospective competition (Pardos-Prado and Xena, 2019). It is therefore in their personal interest to limit competition. Following the predictions of ethnic competition theory, we therefore expect that workers on fixed-term contracts are more opposed to immigration than those on permanent contracts (Hypothesis 1A).

Several authors have argued that anti-immigration attitudes are not triggered by the level of competition, but by a change in competitive conditions (Dancygier and Donnelly, 2013; Lancee and Pardos-Prado, 2013; Meuleman et al., 2009). This leads to the hypothesis that workers on fixed-term contracts become less opposed to immigration when they receive a permanent contract (Hypothesis 1B). 
Exposure to competitive threat is not the same for all fixed-term contract workers. Firstly, the intensity of competition with immigrants for jobs depends on whether employers could hire immigrants to fill these positions. Following Dancygier and Donnelly (2013), we take share of immigrants in a sector as a proxy for replaceability. We expect that the difference in antiimmigration attitudes between fixed-term and permanent contract workers is greater the larger the share of immigrants in the sector of employment (Hypothesis 2).

The intensity of competition also depends on the availability of jobs. We expect that the difference in anti-immigration attitudes between fixed-term and permanent contract workers is greater the higher the sectoral unemployment (Hypothesis 3).

Finally, the extent to which having a fixed-term contract increases exposure to competition depends on the relative security of a permanent contract. Policies that provide a high level of employment protection to workers on permanent contracts and only little to those on fixed-term contracts are known to lead to strong insider-outsider segmentation. In these labor markets, the high turnover costs of replacing permanent employees result in low transition rates between contract types, thus making workers on fixed-term contracts particularly vulnerable (Passaretta and Wolbers, 2019; Polavieja, 2003, 2005). We expect that the difference in anti-immigration attitudes between fixed-term and permanent contract workers is greater the larger the gap in employment protection of permanent vs. temporary contracts (Hypothesis 4).

\section{Cross-national analysis: European Social Sur- vey, 2002-18}

\section{Data and method}

Our analyses draw on nine rounds of the European Social Survey (ESS, 2002, 2004, 2006, 2008, 2010, 2012, 2014, 2016, 2018), collected in the years from 2002-2020. The ESS is a biennial, repeated cross-sectional survey that comprises information from respondents aged 15 years and older in 36 European 
countries. Not all countries participated in all rounds. The quality of the ESS data collection process is generally considered to be very high (Koch et al., 2009), as in all countries random probability samples are drawn and face-to-face interviews are conducted, following standardized procedures and strict quality controls to ensure representativeness and comparability of the data. Country samples comprise on average ca. 1,900 respondents per country and survey round. Although many countries were not able to reach the target response rate of 70 per cent, the average response rate is 60.4 per cent. Further descriptions of the ESS, including more detailed information on data collection and response rates for all countries are available on the ESS web site (europeansocialsurvey.org).

We restrict the sample to respondents aged 25-55 years whose main activity is employment, living in Western Europe, ${ }^{1}$ as we are interested in prime-age workers who have finished full-time education and are not yet approaching retirement. Sample sizes by country and survey round are reported in Table A1.

Anti-immigration attitudes are our outcome variable and are measured based on three questions. The general question wording is 'Now, using this card, to what extent do you think [country] should allow people from [a certain group] to come and live here?' [Country] refers to the country where the interview takes place. Respondents are asked about three groups, namely people from the 'same ethnic group,' 'a different ethnic group,' and from 'poorer countries outside Europe.' Response categories (and values) include: 'allow none' (4), 'allow a few' (3), 'allow some' (2), and 'allow many' (1). The answers to these questions are strongly intercorrelated $(r=.70-.83)$, have a one-dimensional solution in a principal component analysis (explained variance $=.85 \%$ ), and have a Cronbach's alpha of .91 (range across countries from .84 in Greece and Denmark to .96 in Spain). In line with previous studies (e.g. Hainmueller and Hiscox, 2007; Hiers et al., 2017), we averaged the answers across the three questions to obtain a variable ranging from 1 to

\footnotetext{
${ }^{1}$ Specifically, in Austria, Belgium, Denmark, Finland, France, Germany, Greece, Iceland, Ireland, Italy, Luxembourg, the Netherlands, Norway, Portugal, Spain, Sweden, Switzerland, and the United Kingdom.
} 
4, with higher values indicating a stronger anti-immigrant attitude.

Contract type Contract type was measured with a question 'Do/did you have a work contract of unlimited duration (0), or, limited duration (1), or, do/did you have no contract?' In line with previous studies (Balz, 2017), we have removed the minority of cases without a work contract and self-employed respondents from our analyses, as these groups are very heterogeneous, making any differences in attitudes difficult to interpret.

Individual-level control variables We distinguish between male and $f e$ male (male as reference category) respondents and adjust for differences by being foreign-born (native as reference) ${ }^{2}$, education (broken down into low education (less than secondary, reference category), medium education (secondary), and high (tertiary) education), age (in decades) and age squared, and 148 different occupational groups (based on the 3-digit ISCO-88 coding scheme). We also use education as a stratifying variable.

We further stratify our models by social class based on a three-class version of the European Socio-economic Classification (ESEC, Rose and Harrison, 2010). We distinguish between those in the working class (e.g. cleaners or drivers), in intermediate classes (e.g. office clerks), and in the salariat (e.g. lawyers or scientists). We do not include social class as a control variable as most of its variation is captured by the 147 occupation dummies included in the equations.

Higher-level variables We take account of the share of immigrants in an industry, calculated as the the number of immigrants (defined as all foreignborn) divided by the total number of employees, for each 1-digit NACE sector (Eurostat, 2008) by country and year. It is expressed as a percentage on a scale from 0-100. Data come from the EU Labor Force Survey and were

\footnotetext{
${ }^{2}$ While foreign-born respondents and respondents whose parents are foreign-born may be co-ethnics of aspiring immigrants, they would also exposed to labor market competition with the newcomers, making it their personal interest to limit inflow. The outgroup mechanism described in ethnic competition theory also applies here. Several studies show that settled migrant communities see co-ethnic newcomers as outsiders rather than ingroup members (e.g. Charsley and Bolognani, 2017). We therefore include them in our analytical sample.
} 
provided by Eurostat. For rounds 1-3, data are coded following NACE 1.1, for ESS rounds $4-8$ following NACE 2.0. ${ }^{3}$ This data is available for all countries in the ESS microdata.

Sectoral unemployment data also come from the Eurostat and are based on the EU Labor Force Survey. As with share of immigrants, data is matched based on 1-digit NACE sector by country and year. Sectoral unemployment is not available for Norway after 2004 .

The gap in employment protection of permanent vs. fixed-term contracts is measured using the Employment Protection Legislation (EPL) indicators assembled by the OECD (OECD, 2020a). EPL scores for permanent contracts are based on policies for dismissal (such as notification procedures and severance pay). The score for temporary contracts are based on the criteria for hiring (e.g. types of work, maximum contract duration). As Passaretta and Wolbers (2019) argue, both indicators capture turnover costs. The scores are normalized to a 0-6 range, in which higher scores reflect higher levels of protection. Following Passaretta and Wolbers (2019), we use the absolute difference in EPL scores for temporary and permanent contracts. We calculated the gap in scores for each country and year combination. Scores above 0 reflect stronger protection of permanent vs. temporary workers. This data is available for all countries. Data for Luxembourg and Iceland are only available from 2008 onwards.

Analytical strategy In a first step, we make use of ordinary least squares (OLS) regression to analyze the difference in anti-immigration attitudes between those with fixed-term and permanent contracts. We subsequently control for potential confounders of the contract status-immigration attitude relation, namely country and survey round dummies plus their interactions to remove any country- and time-varying confounding, as well as the control variables listed above. For these regression models, we use cluster-robust standard errors that take into account clustering at the country-year level.

In a second step, we explore the difference in attitudes between fixed-term

\footnotetext{
${ }^{3}$ For round 4 (2008-9), ESS employed the NACE 1.1 coding scheme, however Eurostat switched to NACE 2.0 in 2008. We therefore recoded the round 4 industry data from NACE 1.1 to NACE 2.0.
} 
and permanent workers for subgroups. We stratify our analyses by education, social class, and country. In a third step, we test Hypotheses 2-4, assessing how the attitude difference between permanent and fixed-term workers varies by the share of foreign-born in the industry, sectoral unemployment, and the gap in employment protection by including interaction terms for each of these factors.

\section{Results}

Table 1: Descriptive statistics for full sample and by contract type. Proportions unless otherwise stated

\begin{tabular}{lccc}
\hline & Total & Fixed-term & Permanent \\
\hline Anti-immigration attitude (mean $(S D))$ & 2.23 & 2.19 & 2.23 \\
& $(0.75)$ & $(0.78)$ & $(0.75)$ \\
Fixed-term contract & 0.12 & 1.00 & 0.00 \\
Education: & & & \\
$\quad$ Low & 0.16 & 0.21 & 0.16 \\
$\quad$ Medium & 0.42 & 0.34 & 0.43 \\
$\quad$ High & 0.42 & 0.45 & 0.42 \\
Female & 0.49 & 0.56 & 0.49 \\
Foreign-born & 0.12 & 0.18 & 0.11 \\
Age (/10, mean (SD)) & 4.06 & 3.71 & 4.10 \\
$\quad$ & $(0.86)$ & $(0.88)$ & $(0.84)$ \\
Social class: & & & \\
$\quad$ Working class & 0.42 & 0.48 & 0.41 \\
$\quad$ Intermediate & 0.20 & 0.16 & 0.21 \\
$\quad$ Salariat & 0.38 & 0.36 & 0.38 \\
\hline$N \quad 75,911$ & & \\
\hline
\end{tabular}

Source: European Social Survey (2002-18, ESS, 2002, 2004, 2006, 2008, 2010, 2012, 2014, 2016, 2018), own calculations. Note: SD: Standard deviation.

We first examined at the share of fixed-term contract workers in the sample. The average across the sample is twelve per cent (Table 1), which is in line with OECD data. Figure A1 shows the percentage of fixed-term workers by country. Table 1 further reveals that workers with permanent contracts have a slightly stronger anti-immigration attitude compared to fixed-term 
workers, fixed-term workers are both better and worse educated than permanent workers, are more likely to be female, are younger, and working class rather than intermediate class.

Table 2: Anti-immigrant attitude regressed on contract type and control variables, OLS regression, unstandardized coefficients (standard errors in parentheses).

\begin{tabular}{|c|c|c|c|c|c|c|c|c|}
\hline & \multicolumn{2}{|c|}{ Full sample } & \multicolumn{3}{|c|}{ Education } & \multicolumn{3}{|c|}{ Social class } \\
\hline & Model (1) & Model (2) & Low & Medium & High & Working & Intermediate & Salariat \\
\hline Fixed-term contract (Ref. permanent) & $\begin{array}{c}-0.06^{* * *} \\
(0.01)\end{array}$ & $\begin{array}{c}-0.04^{* * *} \\
(0.01)\end{array}$ & $\begin{array}{c}0.01 \\
(0.02)\end{array}$ & $\begin{array}{l}-0.02 \\
(0.01)\end{array}$ & $\begin{array}{c}-0.07^{\text {*** }} \\
(0.01)\end{array}$ & $\begin{array}{c}-0.02 \\
(0.01)\end{array}$ & $\begin{array}{c}-0.04^{*} \\
(0.02)\end{array}$ & $\begin{array}{c}-0.05^{* * *} \\
(0.01)\end{array}$ \\
\hline Female sex (Ref. male) & & $\begin{array}{c}0.04^{* * *} \\
(0.01)\end{array}$ & $\begin{array}{c}0.08^{* * *} \\
(0.02)\end{array}$ & $\begin{array}{c}0.07^{* * *} \\
(0.01)\end{array}$ & $\begin{array}{c}0.00 \\
(0.01)\end{array}$ & $\begin{array}{c}0.06^{* * *} \\
(0.01)\end{array}$ & $\begin{array}{c}0.06^{* * *} \\
(0.01)\end{array}$ & $\begin{array}{c}0.01 \\
(0.01)\end{array}$ \\
\hline Foreign-born (Ref. native) & & $\begin{array}{c}-0.18^{* * *} \\
(0.02)\end{array}$ & $\begin{array}{c}-0.39^{* * *} \\
(0.03)\end{array}$ & $\begin{array}{c}-0.19^{* * *} \\
(0.02)\end{array}$ & $\begin{array}{c}-0.07^{* * *} \\
(0.02)\end{array}$ & $\begin{array}{c}-0.29^{* * *} \\
(0.02)\end{array}$ & $\begin{array}{c}-0.12^{* * *} \\
(0.02)\end{array}$ & $\begin{array}{c}-0.05^{* * *} \\
(0.01)\end{array}$ \\
\hline Medium & & $\begin{array}{c}-0.08^{* * *} \\
(0.01)\end{array}$ & & & & $\begin{array}{c}-0.09^{* * *} \\
(0.01)\end{array}$ & $\begin{array}{c}-0.11^{* * *} \\
(0.02)\end{array}$ & $\begin{array}{c}-0.10^{* * *} \\
(0.03)\end{array}$ \\
\hline High & & $\begin{array}{c}-0.27^{* * *} \\
(0.01)\end{array}$ & & & & $\begin{array}{c}-0.28^{* * *} \\
(0.02)\end{array}$ & $\begin{array}{c}-0.31^{* * *} \\
(0.02)\end{array}$ & $\begin{array}{c}-0.28^{* * *} \\
(0.03)\end{array}$ \\
\hline Age $(/ 10)$ & & $\begin{array}{l}0.01^{* *} \\
(0.00)\end{array}$ & $\begin{array}{c}0.02 \\
(0.01)\end{array}$ & $\begin{array}{c}0.00 \\
(0.01)\end{array}$ & $\begin{array}{l}0.01^{*} \\
(0.01)\end{array}$ & $\begin{array}{l}0.02^{* *} \\
(0.01)\end{array}$ & $\begin{array}{l}-0.00 \\
(0.01)\end{array}$ & $\begin{array}{c}0.01 \\
(0.01)\end{array}$ \\
\hline Age $(/ 10)$ squared & & $\begin{array}{c}0.00 \\
(0.00)\end{array}$ & $\begin{array}{l}-0.01 \\
(0.01)\end{array}$ & $\begin{array}{l}-0.00 \\
(0.01)\end{array}$ & $\begin{array}{c}0.01 \\
(0.01)\end{array}$ & $\begin{array}{l}-0.01 \\
(0.01)\end{array}$ & $\begin{array}{c}0.00 \\
(0.01)\end{array}$ & $\begin{array}{l}0.01^{*} \\
(0.01)\end{array}$ \\
\hline Country and round FE plus interactions & Yes & Yes & Yes & Yes & Yes & Yes & Yes & Yes \\
\hline Average outcome (SD) & $2.23(0.75)$ & $2.23(0.75)$ & $2.54(0.79)$ & $2.34(0.73)$ & $2.00(0.69)$ & $2.42(0.76)$ & $2.21(0.73)$ & $2.02(0.69)$ \\
\hline$N_{\text {respondents }}\left(N_{\text {countries }}\right)$ & $75,911(18)$ & $75,911(18)$ & $12,240(18)$ & $31,788(18)$ & $31,883(18)$ & $31,799(18)$ & $15,165(18)$ & $28,947(18)$ \\
\hline
\end{tabular}

Source: European Social Survey (2002-18, ESS, 2002, 2004, 2006, 2008, 2010, 2012, 2014, 2016, 2018). Notes: Standard errors are cluster-robust at the country-year level. FE: Fixed effects. SD: Standard deviation. ${ }^{*} \mathrm{p}<0.05,{ }^{* *} \mathrm{p}<0.01,{ }^{* * *} \mathrm{p}<0.001$ (two-tailed)

Hypothesis 1A posits that workers on fixed-term contracts are more opposed to immigration than those on permanent contracts. Table 2 provides no support for this Hypothesis. The first model of Table 2 shows an effect pointing in the opposite direction from the one posited in Hypothesis 1A. Workers on fixed-term contracts have a weaker anti-immigration attitude than those with permanent contracts $(b=-.06, p<.001)$. This difference however is substantively small. The standard deviation of the outcome variable anti-immigrant attitude is .75 , thus the difference between the groups amounts to $(-.06 / .75)-.08$ standard deviations.

The second model of Table 2 adds the control variables to the equation. From Table 1 we already know that fixed-term and permanent workers differ considerably in important respects. Adjusting for these differences in 
sex, origin, education, age, as well as controlling for occupation reduces the difference in attitudes between fixed-term and permanent workers to -.04 $(p<.001,-.05 S D)$. Comparing this difference to the attitude differences between educational groups, it shows that the difference between the lower and the medium-educated is twice as big as the difference between fixed-term and permanent workers. The attitude difference between the higher educated and the lower educated is almost seven times as big as the attitude difference between fixed-term and permanent workers. This underlines that the attitude difference between fixed-term and permanent works is substantively small.

Table 2 further conducts subgroup analyses by education and social classtwo factors often seen as key determinants of exposure to competitive threat, controlling for all variables included in the previous model. Models by education reveal that the difference is driven by the higher educated, for those with medium education and low education the difference is not different from zero at conventional levels of statistical significance. The interaction between education and contract type is visualized in Panel A of Figure 1. Models by social class show no relation between contract type and attitudes for the working class, and a substantively small negative relation in the intermediate and salariat classes. These findings all contradict Hypothesis 1A.

Further robustness checks, i.e. controlling for marital status, household income, working hours, and community size (Table A3), and stratifying the sample by sex, partner status (single, single-earner couple, dual-earner couple), and looking at the 'most likely' case (low-educated, single-earner working class individuals) all lead to the same conclusion (Table A4). In addition, we expanded our comparison to include those without a work contract, the unemployed, and the self-employed (Figure A2), showing results that are in line with our key findings.

While the analyses in Table 2 remove all between-country variation, we also conducted analyses to investigate country differences in the size of the attitude difference between fixed-term and permanent workers. Figure 2 shows the result of this exploration-for most countries the coefficient is negative and not statistically different from 0 . The difference in attitudes is only significant in Austria, France, Norway, and Spain, but in the opposite 
A

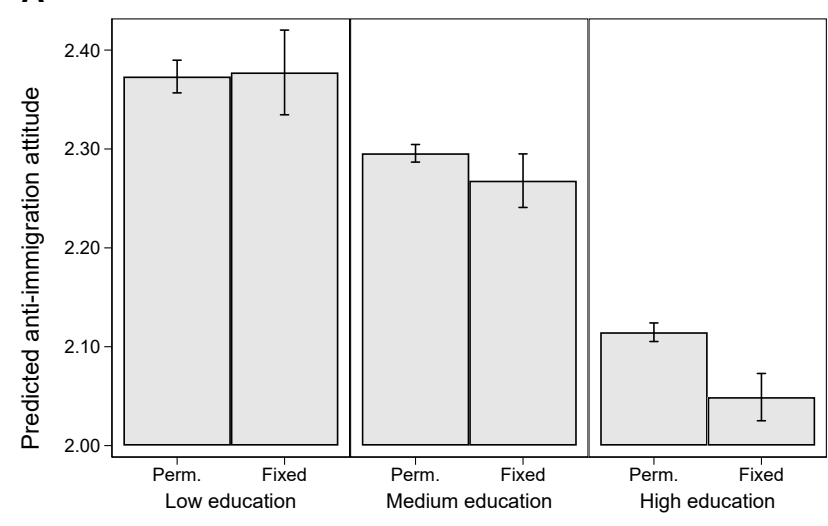

C

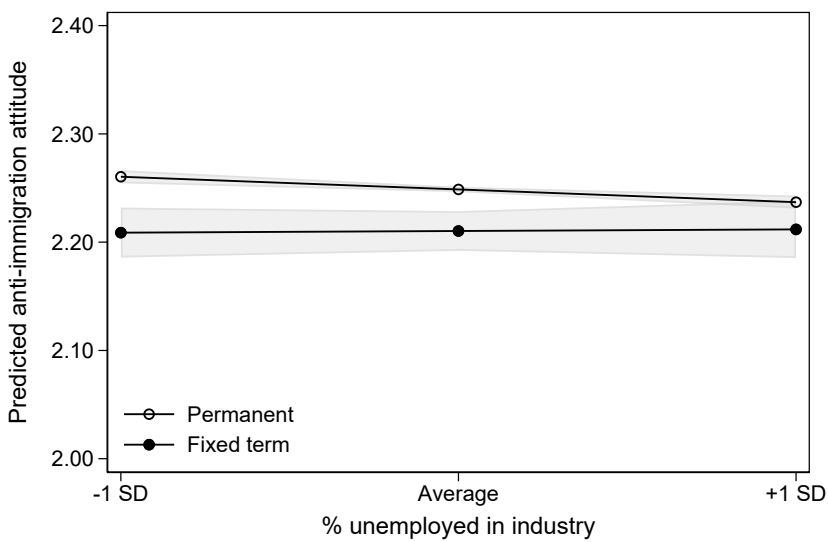

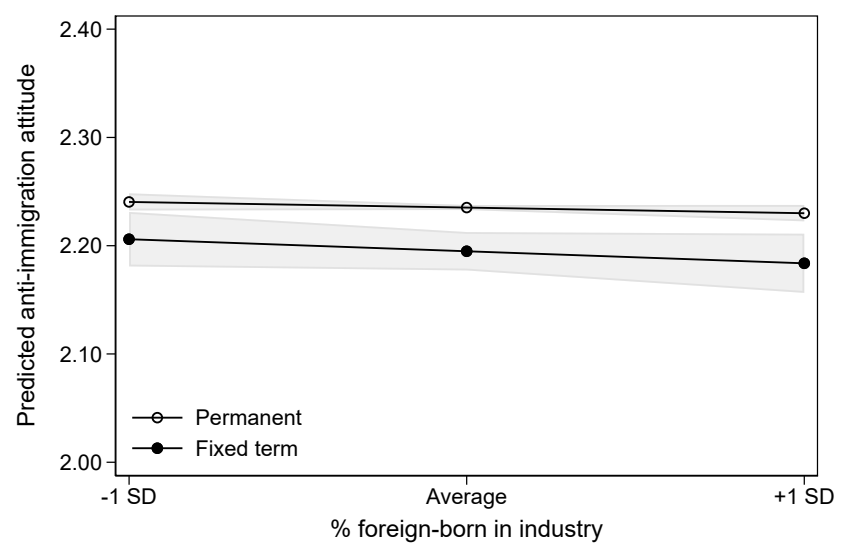

D

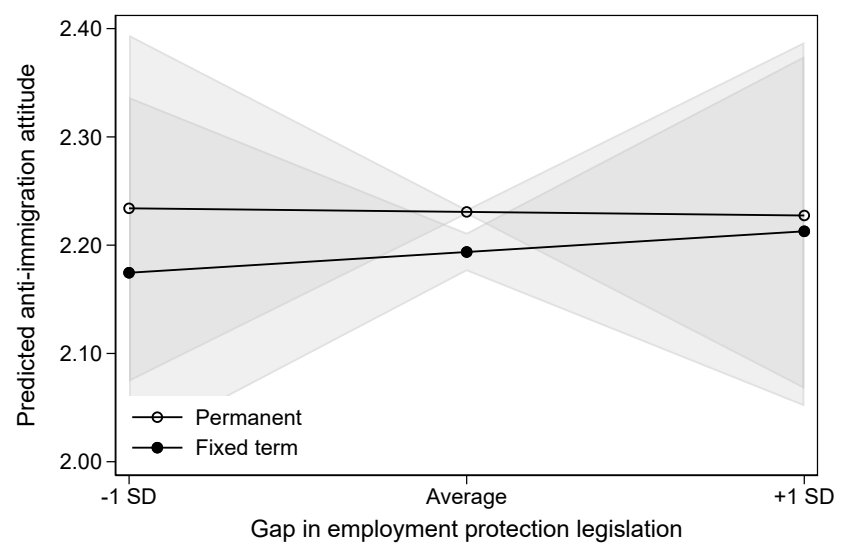

E

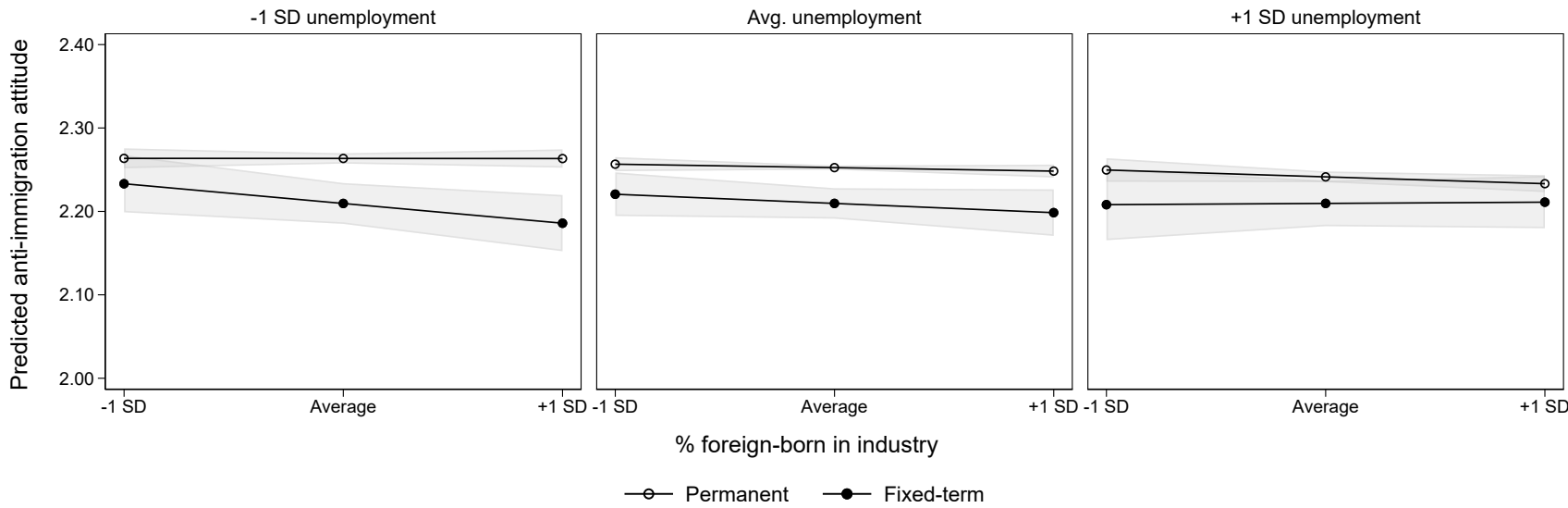

Figure 1: For caption see top of next page 
Figure 1: Panel A: Interaction between contract type and education. Panel B: Interaction between contract type and share of foreign-born in an industry. Panel $C$ : Interaction between contract type and share of unemployed in an industry. Panel $D$ : Interaction between contract type and employment protection legislation (EPL) gap in a country. Panel E: Interaction between contract type, share of unemployed in an industry, and share of foreign-born in an industry.

Continued from previous page: Source: European Social Survey (2002-18, ESS, 2002, 2004, 2006, 2008, 2010, 2012, 2014, 2016, 2018), own calculations. Notes: Panel A: Estimates based on country-specific OLS regression models controlling for all variables listed in Model (2) of Table 2. Error bars denote 95\% confidence intervals based on cluster robust standard errors. Panel B: Estimates based on Model (2) of Table A2. Shaded areas denote $95 \%$ confidence intervals based on standard errors clustered at the country-year level. Panel C: Estimates based on Model (2) of Table A2. Shaded areas denote 95\% confidence intervals based on standard errors clustered at the country-year level. Norway only observed until 2004. Panel D: Estimates based on Model (2) of Table A2. Shaded areas denote $95 \%$ confidence intervals based on standard errors clustered at the country-year level. Luxembourg and Iceland only observed from 2008 onwards. Panel E: Estimates based on Model (2) of Table A2. Shaded areas denote 95\% confidence intervals based on standard errors clustered at the country-year level.

from expected direction. There is no obvious commonality between these four countries that might explain why the attitudinal gap is non-zero here. They vary in their share of fixed-term contracts (Figure A1) and in the level of employment protection.

Hypothesis 2 posited that the difference between fixed-term and permanent contract workers in anti-immigration attitudes is greater the larger the share of immigrants in the sector of employment is. While the average effect of fixed-term contracts on anti-immigration attitudes is thus close to zero, this may hide variation related the sectoral share of immigrant workers. To test the hypothesis, we added the sectoral share of immigrants and the interaction with fixed-term contracts to the model. The results are displayed in Panel B of Figure 1, revealing that fixed-term workers have lower antiimmigration attitudes when there are more foreign-born in their industry. Table A2 shows that the interaction between contract status and share of foreign-born is not statistically significant at conventional levels.

Hypothesis 3 conjectured the relation between contract type and antiimmigrant attitudes is moderated by sectoral unemployment. Panel C of 


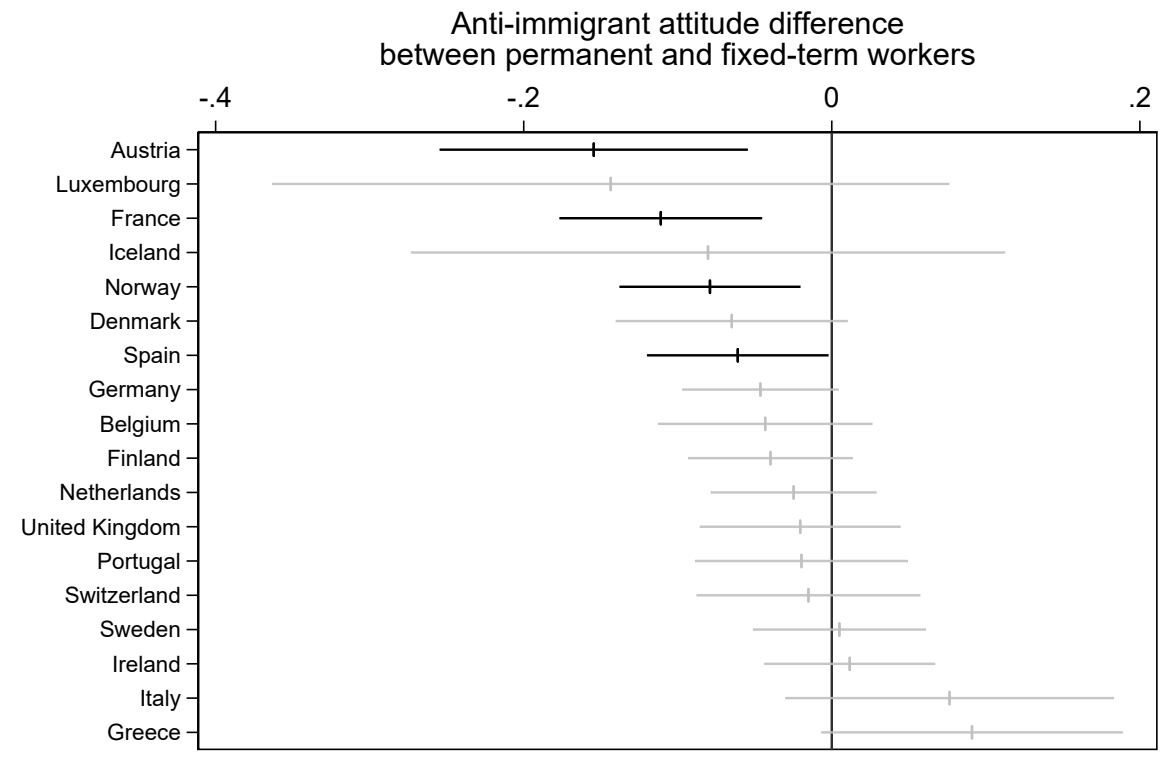

Figure 2: Difference in anti-immigration attitude between fixed-term and permanent workers by country.

Source: European Social Survey (2002-18, ESS, 2002, 2004, 2006, 2008, 2010, 2012, 2014, 2016, 2018), own calculations. Note: Error bars denote 95 per cent confidence intervals. Confidence intervals shown in gray include zero. 
Figure 1 shows this is not the case; there is almost no discernable effect of sectoral unemployment on the anti-immigration attitudes of fixed-term workers. For workers on permanent contracts, there is a very modest decrease in anti-immigration attitudes with higher levels of sectoral unemployment. Table A2 shows that this moderating effect of sectoral unemployment on the relation between contract type and attitudes is not statistically significant at conventional levels.

In a further test of Hypotheses 2 and 3, we also examined the three-way interaction between sectoral share of immigrants, sectoral unemployment, and contract type. Competition should become particularly pronounced when job availability is low, while immigrants' ability to take on these jobs (replaceability) is high. Panel E of Figure 1 shows the interaction between contract type and sectoral share of immigrants at different levels of sectoral unemployment. It shows that the finding from Panel B that fixed-term workers have lower anti-immigration attitudes when shares of foreign-born in their industry are higher is mainly present when unemployment is below average (left-most panel). At above-average unemployment (right-most panel) the moderating role of sectoral immigrant share on the relation between contract type and anti-immigrant attitudes decreases. At both below and above average levels of sectoral unemployment and shares of immigrant workers, however fixed-term contract workers are less anti-immigrant than workers on permanent contracts. Table A2 shows the three-way interaction between unemployment, immigrant shares, and contract type is not statistically significant. These results do not lend support to Hypotheses 2 and 3.

Hypothesis 4 predicted the difference between fixed-term and permanent contract workers in anti-immigration attitudes is greater the larger the gap in employment protection of permanent vs. temporary contracts. Panel D of Figure 1 shows the opposite is the case; the larger the gap in employment protection, the smaller the difference in anti-immigration attitudes between workers on permanent and fixed-term contracts $(b=.02, p<.01)$. Closer inspection reveals that this effect is driven by the EPL score for temporary contracts. While the predicted anti-immigration attitude for fixed-term workers is fairly stable across all levels of employment protection, for permanent workers less protection of fixed-term contracts is associated with lower 
anti-immigrant attitudes.

In sum, our cross-sectional analyses show no support for the role of labor market competition in shaping anti-immigration attitudes.

\section{Longitudinal analysis: German Socio-Economic Panel, 1999-2015}

\section{Data and method}

While the cross-sectional analyses did not reveal evidence for the hypothesized positive relation between fixed-term contracts and anti-immigration attitudes, it is too early to dismiss the role of labor market competition. Firstly, it might be that people on fixed-term contracts differ from those on permanent contracts in ways that also make them less - or at least not more - anti-immigration and that are not captured by the control variables in the models (i.e. are 'unobserved'). For example, it could be that people who are less risk averse are both more likely to have a fixed-term contract and less likely to oppose immigration. Secondly, some have argued that anti-immigration attitudes are caused by changes in competition rather than levels of competition, therefore we should examine the effect of a change in contract status.

To address these two issues, we conducted an analysis of the German Socio-Economic Panel (GSOEP, Goebel et al., 2019; Schupp et al., 2017) for the years 1999-2015. GSOEP is a high-quality household panel study that follows the same respondents over time with annual interviews. Germany is a key case due to its typicality; it experienced several waves of immigration over the past decades and its levels of employment protection and prevalence of fixed-term contracts are close to the median of the countries in the crosssectional analysis. The fact that the data follow individuals over time allows us to account for both observed and unobserved individual characteristics in fixed-effects analyses where individuals essentially serve as their own controls. Further, it allows a test of the dynamic interpretation of ethnic group competition. 
We restrict the sample to individuals between 25 and 55 years of age in paid work to ensure comparability with the ESS analyses.

Concern about migration Our outcome is the answer to the question, 'How concerned are you about immigration to Germany?' with three response options: 'Very concerned,' 'Somewhat concerned,' and 'Not concerned at all.' We coded the answer 'Very concerned' as 1 and the other two response options as 0 . This question, which has been part of the questionnaire in every year since 1999, has been previously validated as a measure for anti-immigrant concern (Lancee and Pardos-Prado, 2013; Pardos-Prado and Xena, 2019), as well-known predictors of anti-immigrant attitudes correlate with the concern question in the same way. Figure 3 shows the trend in the outcome variable over time.

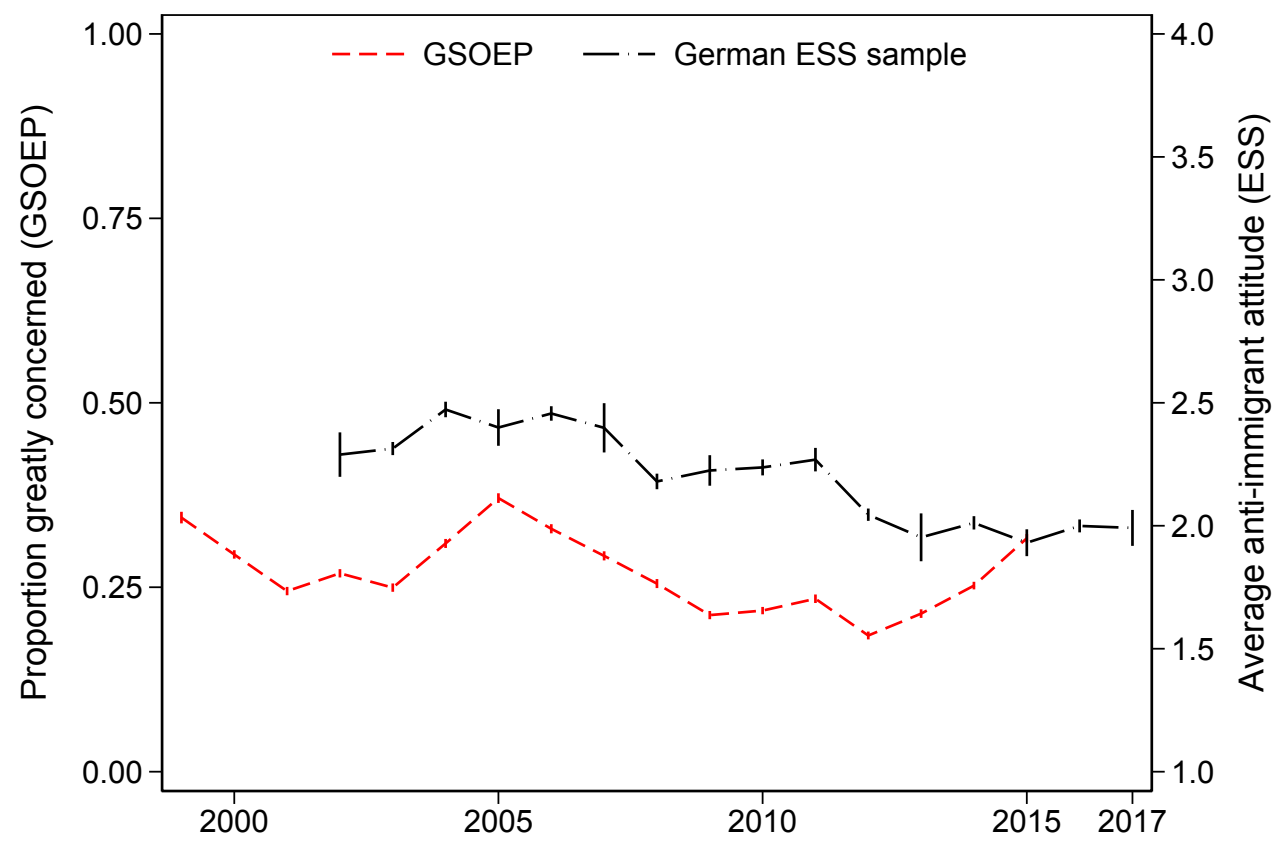

Figure 3: Trend in outcome variables for the German sample of the ESS and the GSOEP sample

Source: German sample of European Social Survey (ESS, 2002-18, ESS, 2002, 2004, 2006, 2008, 2010, 2012, 2014, 2016, 2018) and German Socio-Economic Panel (GSOEP, 19992015, Schupp et al., 2017), own calculations. Note: Spikes denote 95\% confidence intervals. 
Contract type Our key predictor is the contract status of respondents, based on a question 'Do you have a fixed-term or permanent employment contract?' We disregard self-employed respondents as well as those who are not working or without a job contract. Descriptive findings for contract types are reported in Table 3.

Table 3: Descriptive statistics for contract type and contract trajectories

\begin{tabular}{lcc}
\hline Predictor variable & $\begin{array}{c}\text { \% person-year } \\
\text { observations }\end{array}$ & $\begin{array}{c}\text { \% persons experiencing } \\
\text { the state/trajectory }\end{array}$ \\
\hline Contract type & & \\
$\quad$ Permanent & 90.3 & 92.4 \\
$\quad$ Fixed-term & 9.7 & 25.4 \\
Contract trajectory & & 72.5 \\
$\quad$ Permanent $\rightarrow$ permanent & 87.0 & 11.5 \\
Permanent $\rightarrow$ fixed & 3.0 & 16.0 \\
Fixed $\rightarrow$ permanent & 4.3 & 11.5 \\
Fixed $\rightarrow$ fixed & 5.6 & \\
\hline
\end{tabular}

Source: German Socio-Economic Panel (GSOEP, 1999-2015, Schupp et al., 2017), own calculations.

Notes: $N=107,985$ person-years and $N=24,936$ persons

Control variables We include a number of control variables in our analyses. We control for gender and being foreign-born. Note that these timeconstant variables can only be included in the random-effects models. Further, we control for a number of time-varying control variables: age and age ${ }^{2}$, education (lower secondary and below: low, upper secondary: medium, tertiary: high), 110 dummies for occupation based on 3-digit ISCO-88, and survey year dummy variables.

Analytical strategy We conducted linear probability panel regressions with random and fixed-effects specifications. Particularly important here is the fixed-effects specification, where each individual essentially serves as their own control, allowing us to account for all time-constant confounding 
factors (e.g. ability, personality), regardless of whether these are observed or not. This is a major advantage over the ESS analyses, which hinged on the assumption that all relevant differences between fixed-term and permanent workers had been observed.

\section{Results}

Results for the analysis of GSOEP data are reported in Table 4. Having a fixed-term contract is associated with greater concern about immigration only in the random effects specification. The effect size here is substantively small, having a fixed-term contract goes along with a one-percent greater probability of being concerned about immigration. The fixed-effects specification shows that this association is due to unobserved time-constant confounders - i.e. stable differences between workers on fixed-term and permanent contracts not captured in the model-, as the relationship becomes smaller and statistically insignificant once all time-constant factors are accounted for. This further supports our rejection of Hypothesis 1A which posited that workers on fixed-term contracts are more opposed to immigration than those on permanent contracts.

The models on the right of Table 4 test Hypothesis 1B, which holds that workers changing from a fixed-term to a permanent contract become less concerned about immigration. While the coefficients for this transition do point in this direction, they are far from reaching conventional levels of statistical significance and substantively small. We thus also do not find support of Hypothesis 1B.

Predictions in Panels A and B of Figure 4 provide a second test of Hypothesis 2, which holds that differences between fixed-term and permanent workers are greater when the share of foreigners in an industry is greater. Panel A of Figure 4 suggests that the opposite is the case, yet not at conventional levels of statistical significance. Panel B further emphasizes that there are no significant differences when looking at the different transitions of contract types. Hence, we also do not find support for Hypothesis 2 for the German case.

Finally, Panels C and D offer a second test on Hypothesis 3 which as- 
serted that differences in attitudes become larger with higher unemployment. Panel $\mathrm{C}$ shows that this is not the case, the difference is stable and even minimally - but not significantly - decreasing with higher unemployment levels. Panel D shows there are no significant differences in the relation between transition types and attitudes over sectoral unemployment. We thus do not find support for Hypothesis 3 in the German case.

Table 4: Concern about immigration and contract type, random- and fixedeffects LPM panel regression models (robust standard errors in parentheses)

\begin{tabular}{|c|c|c|c|c|c|c|}
\hline & \multicolumn{4}{|c|}{ Contract type } & \multicolumn{2}{|c|}{ Transition type } \\
\hline & $\mathrm{RE}$ & $\mathrm{RE}$ & $\mathrm{FE}$ & $\mathrm{FE}$ & $\mathrm{FE}$ & $\mathrm{FE}$ \\
\hline Fixed-term contract (Ref. permanent) & $\begin{array}{l}-0.000 \\
(0.004)\end{array}$ & $\begin{array}{l}0.010^{*} \\
(0.004)\end{array}$ & $\begin{array}{c}0.007 \\
(0.005)\end{array}$ & $\begin{array}{c}0.007 \\
(0.005)\end{array}$ & & \\
\hline \multicolumn{7}{|c|}{ Contract type transitions (Ref. permanent $\rightarrow$ permanent) } \\
\hline Permanent $\rightarrow$ fixed & & & & & $\begin{array}{l}0.007 \\
(0.008)\end{array}$ & $\begin{array}{c}0.007 \\
(0.008)\end{array}$ \\
\hline Fixed $\rightarrow$ permanent & & & & & $\begin{array}{l}-0.005 \\
(0.006)\end{array}$ & $\begin{array}{l}-0.006 \\
(0.006)\end{array}$ \\
\hline Fixed $\rightarrow$ fixed & & & & & $\begin{array}{l}0.001 \\
(0.008)\end{array}$ & $\begin{array}{l}-0.000 \\
(0.008)\end{array}$ \\
\hline Female (Ref. male) & & $\begin{array}{l}-0.002 \\
(0.004)\end{array}$ & & & & \\
\hline Foreign-born (Ref. native) & & $\begin{array}{c}-0.120^{* * *} \\
(0.005)\end{array}$ & & & & \\
\hline Age & & $\begin{array}{l}-0.000 \\
(0.002)\end{array}$ & & $\begin{array}{l}-0.006^{*} \\
(0.003)\end{array}$ & & $\begin{array}{l}-0.005 \\
(0.003)\end{array}$ \\
\hline Age squared & & $\begin{array}{l}0.000 \\
(0.000)\end{array}$ & & $\begin{array}{l}0.000^{* *} \\
(0.000)\end{array}$ & & $\begin{array}{l}0.000^{* *} \\
(0.000)\end{array}$ \\
\hline \multicolumn{7}{|l|}{ Education (Ref. low) } \\
\hline Medium & & $\begin{array}{c}-0.029^{* * *} \\
(0.007)\end{array}$ & & $\begin{array}{c}0.030 \\
(0.017)\end{array}$ & & $\begin{array}{l}-0.031 \\
(0.041)\end{array}$ \\
\hline High & & $\begin{array}{c}-0.116^{* * *} \\
(0.008)\end{array}$ & & $\begin{array}{l}0.038^{*} \\
(0.019)\end{array}$ & & $\begin{array}{l}-0.030 \\
(0.042)\end{array}$ \\
\hline Intercept & $\begin{array}{c}0.317^{* * *} \\
(0.006)\end{array}$ & $\begin{array}{l}0.381^{* * *} \\
(0.044)\end{array}$ & $\begin{array}{c}0.301^{* * *} \\
(0.006)\end{array}$ & $\begin{array}{c}0.327^{* * *} \\
(0.066)\end{array}$ & $\begin{array}{c}0.272^{* * *} \\
(0.006)\end{array}$ & $\begin{array}{c}0.322^{* * *} \\
(0.080)\end{array}$ \\
\hline 110 Occupation FE & No & Yes & No & Yes & No & Yes \\
\hline Year FE included & Yes & Yes & Yes & Yes & Yes & Yes \\
\hline$N_{\text {observations }}$ & 130,498 & 130,498 & 130,498 & 130,498 & 107,985 & 107,985 \\
\hline$N_{\text {individuals }}$ & 29,576 & 29,576 & 29,576 & 29,576 & 23,411 & 23,411 \\
\hline
\end{tabular}

\section{Discussion}

The recent success of anti-immigration parties and politicians across the Global North has been linked to economic insecurity (Rooduijn and Bur- 
A

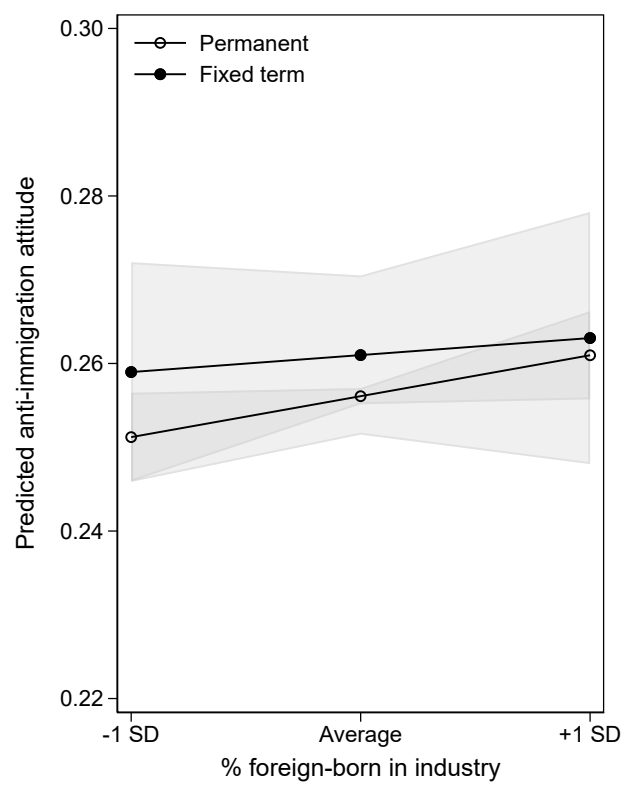

C

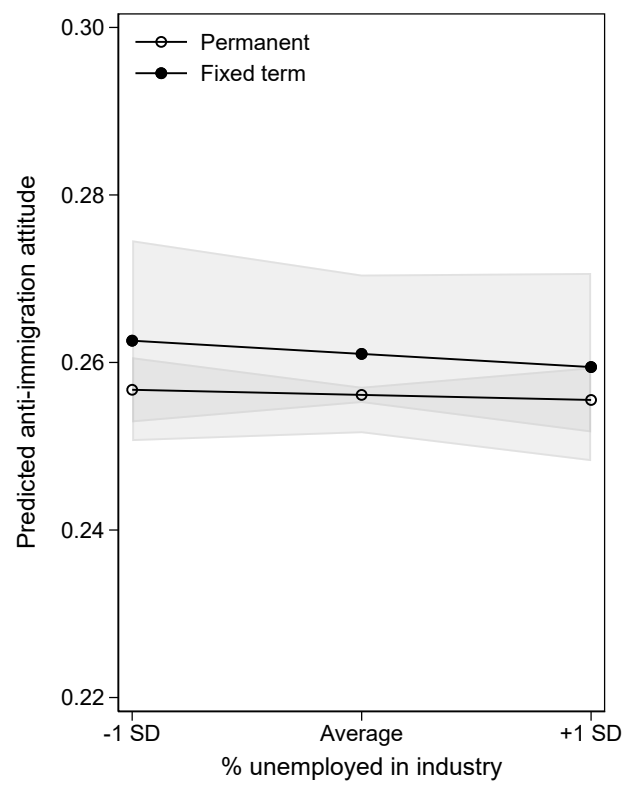

B

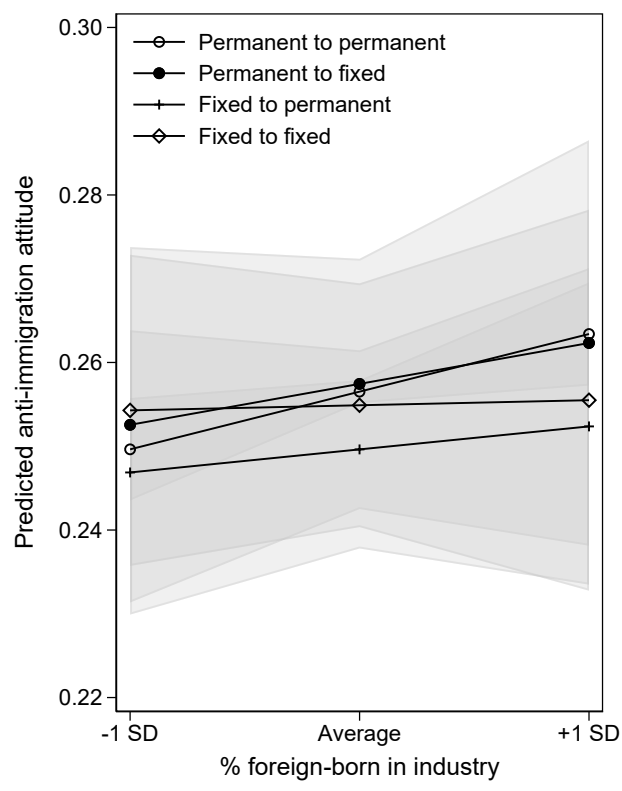

D

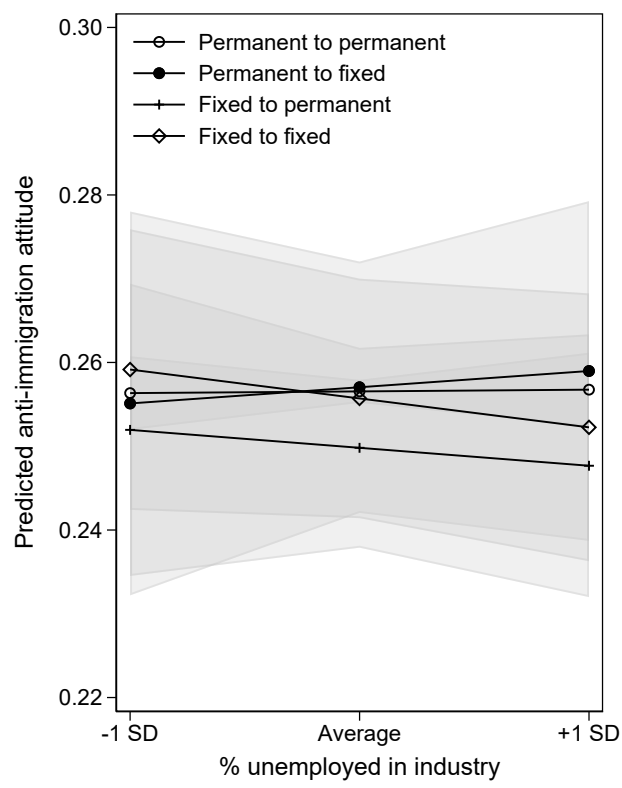

Figure 4: Panel A: Interaction between contract type and share of foreigners in an industry. Panel $B$ : Interaction between contract type transition and share of foreigners in an industry. Panel $C$ : Interaction between contract type and share of unemployed in an industry. Panel B: Interaction between contract type transition and share of unemployed in an industry.

Source: German Socio-Economic Panel (GSQEP, 1999-2015, Schupp et al., 2017), own calculations. Note: Shaded areas denote $95 \%$ confidence intervals based on robust standard errors. Models used for the predictions are shown in Tables A5 and A6. 
goon, 2017; Vlandas and Halikiopoulou, 2022). A key economic trend that has worsened labor market conditions of many Europeans is the proliferation of fixed-term contracts. Workers with fixed-term contracts are more likely to be competing for jobs with migrants in the foreseeable future than workers with permanent work contracts. We argue that following ethnic competition theory, this prospective competition should consequently lead fixed-term workers to more strongly oppose immigration. This study addresses critiques on earlier studies that focused on factors which are not only associated with competition but also with general attitude formation-for example education or job skills-, as contract type cuts across these factors.

The results of our analyses showed little support for ethnic competition theory. Differences found between fixed-term and permanent workers in their opinions about migration were substantively small and often not in the expected direction. Even when controlling for education, age, occupation, and other confounders, fixed-term workers held similar or even more favorable opinions towards immigration than workers with permanent contracts. This finding held across 18 Western European countries in a cross-sectional analysis and in a longitudinal analysis of panel data from Germany, a typical case for ethnic competition theory. Our finding also holds across factors that influence exposure to competition. Although we did find evidence of a (modest) moderating effect of the gap in employment protection of permanent vs. fixed-term contract workers, the direction of effect was opposed to that hypothesized. We found no evidence that the relation between contract type and anti-immigrant attitudes is moderated by sectoral unemployment. This lack of evidence might flow from the high level of aggregation at which sectoral unemployment was measured (1-digit NACE). We mitigate some of that by controlling for participants' detailed occupational group.

While fixed-term contracts increase exposure to competition, they do not necessarily increase exposure to competition with migrants. Our analyses do not include a direct measure of competition with migrants. However, even under conditions when competition is most likely to be with migrants - i.e. in sectors with higher shares of foreign-born workers and for people in working class occupations - we do not find support for ethnic competition theory.

Raess and Burgoon (2015) found that companies with higher shares of 
foreign-born workers, are more likely to introduce fixed-term contracts. This may reflect quality sorting; companies that often employ immigrants, draw workers with comparatively low productivity willing to work on fixed-term contracts (cf. Pecoraro and Ruedin, 2020). Following Allport's (1954) contact hypothesis, this contact with immigrants leads to less anti-immigration attitudes. The negative effect of contact with immigrant co-workers may counteract any positive effect of increased competition for fixed-term contract workers on anti-immigration attitudes. In our analyses we included the sectoral share of immigrants as a proxy for the likelihood an immigrant could take over a job. However immigrant share is likely to also be related to contact with immigrants in the workplace. Our analyses show no (cross-sectional) or a positive effect (longitudinal) effect of sectoral share of immigrants on anti-immigration attitudes. This makes it unlikely that there is an underlying competition effect that is countered by contact experiences.

Strikingly, while our analyses of the German panel data showed no relation between increased job security and concern about immigration, a study using an earlier version of the same data found a relation between job loss and concern about immigration (Lancee and Pardos-Prado, 2013). Similarly, additional analyses of the ESS data show that the unemployed are more opposed to immigration that those employed on either permanent contracts or fixed-term contracts (Figure A2). This discrepancy might be because people respond stronger to loss (of employment) than to gain (of a more secure contract) (Kahneman and Tversky, 1979; Breen, 1997). That we do not find an effect of the transition from permanent to fixed-term contract either, may be due to the voluntary nature of a substantial part of these transitions. The role of loss vs. gain may explain why Dancygier and Donnelly (2013) only found an effect of sectoral shrinkage and of immigrant inflow during an economic crisis: it is not increasing actual competition that leads to a sense of ethnic competition, but (increasing) competition at a time when people have a realistic fear or experience of job loss. This finding further underlines the importance of economic loss as a cross-cutting narrative in contemporary western societies (Jackson and Grusky, 2018; Paskov et al., 2021).

The effect of loss vs. gain could be explored by studying zero-hour contracts. Such contracts do not specify a minimum number of working hours 
for an employee. Employees work on a demand basis and are only paid for the hours worked. This kind of contract is common in the Netherlands, United Kingdom, and Austria (European Parliament, 2016). If a sense of ethnic competition is triggered by loss, workers on zero-hour contracts who experienced a recent drop in average working hours should be more prone to express anti-immigration attitudes than those who experienced a stable or increasing number of hours.

Sub-group analyses reveal that unexpected lower levels of opposition to immigration among fixed-term contract workers compared to those on permanent contracts are mainly driven by the higher educated and those in higher occupational classes - and by workers who are single. This is particularly striking as other studies found support for certain measures of the role of competition only for the higher educated and/or higher occupational classes (Ortega and Polavieja, 2012; Pecoraro and Ruedin, 2020). These contrasting results may be due to self-selection into certain occupations and contract type - and possibly an interaction between the two - that is not properly captured by the controls in our models. One factor that has been receiving more attention is the role of personality traits (Gallego and Pardos-Prado, 2014; Polavieja, 2016). As the results from the longitudinal analyses in this study do not support ethnic competition theory either, self-selection is unlikely to explain why we do not find support for ethnic competition theory in our cross-sectional analyses.

Our findings add to the evidence from earlier research suggesting that factors other than individual economic prospects are the drivers of attitudes towards migration. While insecure contracts are known to impact people's attitudes and life courses, they do not seem affect anti-immigration attitudes.

\section{References}

Allport, Gordon Willard, 1954. The Nature of Prejudice. Reading, MA: Addison-Wesley.

Balz, Anne, 2017. 'Cross-National Variations in the Security Gap. Perceived Job Insecurity among Temporary and Permanent Employees and Employ- 
ment Protection Legislation.' European Sociological Review 33(5). doi: $10.1093 /$ esr $/$ jcx067.

Billiet, Jaak, Bart Meuleman, and Hans de Witte, 2014. 'The Relationship between Ethnic Threat and Economic Insecurity in Times of Economic Crisis. Analysis of European Social Survey Data.' Migration Studies 2(2): 135-161. doi: 10.1093/migration/mnu023.

Blalock, Jr., Hubert M., 1967. Toward a Theory of Minority-Group Relations. New York: Wiley.

Bobo, Lawrence, 1988. 'Attitudes Toward the Black Political Movement. Trends, Meaning, and Effects on Racial Policy Preferences.' Social Psychology Quarterly 51(4): 287-302. doi: 10.2307/2786757.

Breen, Richard, 1997. 'Risk, Recommodification, and Stratification.' Sociology 31(3): 473-489. doi: 10.1177/0038038597031003006.

Cavaille, Charlotte and John Marshall, 2019. 'Education and AntiImmigration Attitudes. Evidence from Compulsory Schooling Reforms across Western Europe.' American Political Science Review 113(1): 254263. doi: 10.1017/S0003055418000588.

Charsley, Katharine and Marta Bolognani, 2017. 'Being a Freshie Is (Not) Cool. Stigma, Capital, and Disgust in British Pakistani Stereotypes of New Subcontinental Migrants.' Ethnic and Racial Studies 40(1): 43-62. doi: 10.1080/01419870.2016.1145713.

Citrin, Jack, Donald P. Green, Christopher Muste, and Cara Wong, 1997. 'Public Opinion toward Immigration Reform. The Role of Economic Motivations.' Journal of Politics 59(3): 858-881. doi: 10.2307/2998640.

Czaika, Mathias and Armando Di Lillo, 2018. 'The Geography of AntiImmigrant Attitudes across Europe 2002-14.' Journal of Ethnic and Migration Studies 44(15): 2453-2479. doi: 10.1080/1369183X.2018.1427564.

Dancygier, Rafaela M. and Michael J. Donnelly, 2013. 'Sectoral Economies, Economic Contexts, and Attitudes toward Immigration.' Journal of Politics 75(1): 17-35. doi: 10.1017/S0022381612000849. 
Erlinghagen, Marcel, 2008. 'Self-Perceived Job Insecurity and Social Context. A Multi-Level Analysis of 17 European Countries.' European Sociological Review 24(2): 183-197. doi: 10.1093/esr/jcm042.

Ersanilli, Evelyn and Patrick Präg, 2021. 'Replication Files to: Fixed-Term Work Contracts and Anti-Immigration Attitudes. A Novel Test of Ethnic Competition Theory.' Open Science Framework doi: 10.17605/OSF.IO/DY6N2.

ESS, 2002. European Social Survey Round 1. Bergen: NSD Norwegian Center for Research Data. doi: 10.21338/NSD-ESS1-2002.

—_, 2004. European Social Survey Round 2. Bergen: NSD Norwegian Center for Research Data. doi: 10.21338/NSD-ESS2-2004.

—, 2006. European Social Survey Round 3. Bergen: NSD Norwegian Center for Research Data. doi: 10.21338/NSD-ESS3-2006.

- 2008. European Social Survey Round 4. Bergen: NSD Norwegian Center for Research Data. doi: 10.21338/NSD-ESS4-2008.

— , 2010. European Social Survey Round 5. Bergen: NSD Norwegian Center for Research Data. doi: 10.21338/NSD-ESS5-2010.

- 2012. European Social Survey Round 6. Bergen: NSD Norwegian Center for Research Data. doi: 10.21338/NSD-ESS6-2012.

—, 2014. European Social Survey Round \%. Bergen: NSD Norwegian Center for Research Data. doi: 10.21338/NSD-ESS7-2014.

—, 2016. European Social Survey Round 8. Bergen: NSD Norwegian Center for Research Data. doi: 10.21338/NSD-ESS8-2016.

—, 2018. European Social Survey Round 9. Bergen: NSD Norwegian Centre for Research Data. doi: 10.21338/NSD-ESS9-2018.

European Parliament, 2016. Precarious Employment in Europe. Brussels: European Union. doi: 10.2861/866485. 
Eurostat, 2008. NACE Rev. 2. Statistical Classification of Economic Activites in the European Community. Luxembourg: Office for Official Publications of the European Communities.

Gallego, Aina and Sergi Pardos-Prado, 2014. 'The Big Five Personality Traits and Attitudes towards Immigrants.' Journal of Ethnic and Migration Studies 40(1): 79-99. doi: 10.1080/1369183X.2013.826131.

Goebel, Jan, M. Grabka Markus, Stefan Liebig, Martin Kroh, David Richter, Carsten Schröder, and Jürgen Schupp, 2019. 'The German Socio-Economic Panel (GSOEP).' Journal of Economics and Statistics 239(2): 345-360. doi: $10.1515 /$ jbnst-2018-0022.

Güveli, Ayse, Ariana Need, and Nan Dirk de Graaf, 2007. 'The Rise of 'New' Social Classes within the Service Class in The Netherlands. Political Orientation of Social and Cultural Specialists and Technocrats between 1970 and 2003.' Acta Sociologica 50(2): 129-146. doi: 10.1177/0001699307077655.

Hainmueller, Jens and Michael J. Hiscox, 2007. 'Educated Preferences. Explaining Attitudes Toward Immigration in Europe.' International Organization 61(2): 399-442. doi: 10.1017/S0020818307070142.

— , 2010. 'Attitudes Towards Highly Skilled and Low Skilled Immigration. Evidence from a Survey Experiment.' American Political Science Review 101(4): 61-84. doi: 10.1017/S0003055409990372.

Hainmueller, Jens, Michael J. Hiscox, and Yotam Margalit, 2015. 'Do Concerns about Labor Market Competition Shape Attitudes Toward Immigration? New Evidence.' Journal of International Economics 97(1): 193-207. doi: 10.1016/j.jinteco.2014.12.010.

Hainmueller, Jens and Daniel J. Hopkins, 2014. 'Public Attitudes Toward Immigration.' Annual Review of Political Science 17: 225-249. doi: 10.1146/annurev-polisci-102512-194818.

—_ 2015. 'The Hidden American Immigration Consensus. A Conjoint Analysis of Attitudes toward Immigrants.' American Journal of Political Science 59(3): 529-548. doi: 10.1111/ajps.12138. 
Heath, Anthony F. and Lindsay Richards, 2019. 'How Do Europeans Differ in Their Attitudes to Immigration? Findings from the European Social Survey 2002/03-16/17.' OECD Social, Employment, and Migration Working Papers 222: 1-40. doi: 10.1787/0adf9e55-en.

- 2020. 'Contested Boundaries. Consensus and Dissensus in European Attitudes to Immigration.' Journal of Ethnic and Migration Studies 46(3): 489-511. doi: 10.1080/1369183X.2018.1550146.

Heizmann, Boris, 2015. 'Social Policy and Perceived Immigrant Labor Market Competition in Europe. Is Prevention Better Than Cure?' Social Forces 93(4): 1655-1685. doi: 10.1093/sf/sou116.

Helbling, Marc and Hanspeter Kriesi, 2014. 'Why Citizens Prefer HighOver Low-Skilled Immigrants. Labor Market Competition, Welfare State, and Deservingness.' European Sociological Review 30(5): 595-614. doi: 10.1093/esr/jcu061.

Hello, Evelyn, Peer Scheepers, and Peter Sleegers, 2006. 'Why the More Educated Are Less Inclined to Keep Ethnic Distance. An Empirical Test of Four Explanations.' Ethnic and Racial Studies 29(5): 959-985. doi: 10.1080/01419870600814015.

Hiers, Wesley, Thomas Soehl, and Andreas Wimmer, 2017. 'National Trauma and the Fear of Foreigners. How Past Geopolitical Threat Heightens Anti-Immigration Sentiment Today.' Social Forces 96(1): 361-388. doi: $10.1093 / \mathrm{sf} / \mathrm{sox} 045$.

Jackson, Michelle and David B. Grusky, 2018. 'A Post-Liberal Theory of Stratification.' British Journal of Sociology 69(4): 1096-1133. doi: 10.1111/1468-4446.12505.

Kahneman, Daniel and Amos Tversky, 1979. 'Prospect Theory. An Analysis of Decision under Risk.' Econometrica 47(2): 263-291. doi: $10.2307 / 1914185$. 
Koch, Achim, Annelies G. Blom, Ineke Stoop, and Joost Kappelhof, 2009. 'Data Collection Quality Assurance in Cross-National Surveys. The Example of the ESS.' Methods Data Analyses 3(2): 219-247. doi: 10.12758/mda.2009.014.

Kuntz, Anabel, Eldad Davidov, and Moshe Semyonov, 2017. 'The Dynamic Relations between Economic Conditions and Anti-Immigrant Sentiment. A Natural Experiment in Times of the European Economic Crisis.' International Journal of Comparative Sociology 58(5): 392-415. doi: 10.1177/0020715217690434.

Lancee, Bram and Sergi Pardos-Prado, 2013. 'Group Conflict Theory in a Longitudinal Perspective. Analyzing the Dynamic Side of Ethnic Competition.' International Migration Review 47(1): 106-131. doi: 10.1111/imre.12015.

Malhotra, Neil, Yotam Margalit, and Cecilia Hyunjung Mo, 2013. 'Economic Explanations for Opposition to Immigration. Distinguishing between Prevalence and Conditional Impact.' American Journal of Political Science 57(2): 391-410. doi: 10.1111/ajps.12012.

Margaryan, Shushanik, Annemarie Paul, and Thomas Siedler, 2019. 'Does Education Affect Attitudes towards Immigration? Evidence from Germany.' Journal of Human Resources doi: 10.3368/jhr.56.2.0318-9372R1.

Marx, Paul, 2014. 'Labour Market Risks and Political Preferences. The Case of Temporary Employment.' European Journal of Political Research 53(1): 136-159. doi: 10.1111/1475-6765.12027.

Marx, Paul and Georg Picot, 2013. 'The Party Preferences of Atypical Workers in Germany.' Journal of European Social Policy 23(2): 164-178. doi: $10.1177 / 0958928712471222$.

— , 2020. 'Three Approaches to Labor Market Vulnerability and Political Preferences.' Political Science Research and Methods 8(2): 356-361. doi: 10.1017/psrm.2018.29. 
McLaren, Lauren M., 2003. 'Anti-Immigrant Prejudice in Europe. Contact, Threat Perception, and Preferences for the Exclusion of Migrants.' Social Forces 81(3): 909-936. doi: 10.1353/sof.2003.0038.

Meuleman, Bart, Eldad Davidov, and Jaak Billiet, 2009. 'Changing Attitudes toward Immigration in Europe 2002-07. A Dynamic Group Conflict Theory Approach.' Social Science Research 38(2): 352-365. doi: 10.1016/j.ssresearch.2008.09.006.

Naumann, Elias, Lukas F. Stoetzer, and Giuseppe Pietrantuono, 2018. 'Attitudes towards Highly Skilled and Low-Skilled Immigration in Europe. A Survey Experiment in 15 European Countries.' European Journal of Political Research 57(4): 1009-1030. doi: 10.1111/1475-6765.12264.

OECD, 2020a. Strictness of Employment Protection Legislation. Paris: Organisation for Economic Co-Operation and Development. doi: 10.1787/lfsdata-en.

— , 2020b. Temporary Employment. Paris: Organisation for Economic Co-Operation and Development. doi: 10.1787/75589b8a-en.

Oesch, Daniel, 2012. 'The Class Basis of the Cleavage between the New Left and the Radical Right. An Analysis for Austria, Denmark, Norway, and Switzerland.' In Rydgren, Jens, ed., Class Politics and the Radical Right, pp. 31-52. London: Routledge. doi: 10.4324/9780203079546-8.

Olzak, Susan, 1992. The Dynamics of Ethnic Competition and Conflict. Stanford, CA: Stanford University Press.

O'Rourke, Kevin H. and Richard Sinnott, 2006. 'The Determinants of Individual Attitudes towards Immigration.' European Journal of Political Economy 22(4): 838-861. doi: 10.1016/j.ejpoleco.2005.10.005.

Ortega, Francesc and Javier G. Polavieja, 2012. 'Labor-Market Exposure as a Determinant of Attitudes Toward Immigration.' Labour Economics 19(3): 298-311. doi: 10.1016/j.labeco.2012.02.004. 
Pardos-Prado, Sergi and Carla Xena, 2019. 'Skill Specificity and Attitudes toward Immigration.' American Journal of Political Science 63(2): 286304. doi: 10.1111/ajps.12406.

Paskov, Marii, Patrick Präg, and Lindsay Richards, 2021. 'Does Downward Social Mobility Make People More Hostile Towards Immigrants?' Research in Social Stratification and Mobility 72(100543): 1-11. doi: 10.1016/j.rssm.2020.100543.

Passaretta, Giampiero and Maarten H.J. Wolbers, 2019. 'Temporary Employment at Labor Market Entry in Europe. Labor Market Dualism, Transitions to Secure Employment and Upward Mobility.' Economic and Industrial Democracy 40(2): 382-408. doi: 10.1177/0143831X16652946.

Pavlopoulos, Dimitris, 2013. 'Starting Your Career With a Fixed-Term Job. Stepping-Stone or Dead End?' Review of Social Economy 71(4): 474-501. doi: 10.1080/00346764.2013.799970.

Pecoraro, Marco and Didier Ruedin, 2016. 'A Foreigner who Does Not Steal My Job. The Role of Unemployment Risk and Values in Attitudes toward Equal Opportunities.' International Migration Review 50(3): 628-666. doi: 10.1111/imre.12162.

— , 2020. 'Occupational Exposure to Foreigners and Attitudes Towards Equal Opportunities.' Migration Studies 8(3): 382-423. doi: 10.1093/migration/mnz006.

Polavieja, Javier G., 2003. 'Temporary Contracts and Labor Market Segmentation in Spain. An Employment-Rent Approach.' European Sociological Review 19(5): 501-517. doi: 10.1093/esr/19.5.501.

- 2005. 'Flexibility or Polarization? Temporary Employment and Job Tasks in Spain.' Socio-Economic Review 3(2): 233-258. doi: 10.1093/SER/mwi010.

_ 2016. 'Labor-Market Competition, Recession, and Anti-Immigrant Sentiments in Europe. Occupational and Environmental Drivers of 
Competitive Threat.' Socio-Economic Review 14(3): 395-417. doi: 10.1093/ser/mww002.

Raess, Damian and Brian Burgoon, 2015. 'Flexible Work and Immigration in Europe.' British Journal of Industrial Relations 53(1): 94-111. doi: 10.1111/bjir.12022.

Rooduijn, Matthijs and Brian Burgoon, 2017. 'The Paradox of Wellbeing. Do Unfavorable Socioeconomic and Sociocultural Contexts Deepen or Dampen Radical Left and Right Voting Among the Less Well-Off?' Comparative Political Studies 51(13): 1720-1753. doi: 10.1177/0010414017720707.

Rose, David and Eric Harrison, 2010. Social Class in Europe. An Introduction to the European Socio-Economic Classification. London: Routledge. doi: 10.4324/9780415534239.

Scheepers, Peer, Mérove Gijsberts, and Marcel Coenders, 2002. 'Ethnic Exclusionism in European Countries. Public Opposition to Civil Rights for Legal Migrants as a Response to Perceived Ethnic Threat.' European Sociological Review 18(1): 17-34. doi: 10.1093/esr/18.1.17.

Scheve, Kenneth F. and Matthew J. Slaughter, 2001. 'Labor Market Competition and Individual Preferences over Immigration Policy.' Review of Economics and Statistics 83(1): 133-145. doi: 10.1162/003465301750160108.

Schneider, Silke L., 2008. 'Anti-Immigrant Attitudes in Europe. Outgroup Size and Perceived Ethnic Threat.' European Sociological Review 24(1): 53-67. doi: 10.1093/esr/jcm034.

Schupp, Jürgen, Jan Goebel, Martin Kroh, Carsten Schröder, Charlotte Bartels, Klaudia Erhardt, Alexandra Fedorets, Marco Giesselmann, Markus Grabka, Peter Krause, Simon Kühne, David Richter, Rainer Siegers, Paul Schmelzer, Christian Schmitt, Daniel Schnitzlein, and Knut Wenzig, 2017. German Socio-Economic Panel 1984-2015. Berlin: German Institute for Economic Research. doi: 10.5684/soep.v32.

Tolsma, Jochem, Marcel Lubbers, and Marcel Coenders, 2007. 'Ethnic Competition and Opposition to Ethnic Intermarriage in the Netherlands. A 
Multi-Level Approach.' European Sociological Review 24(2): 215-230. doi: 10.1093/esr/jcm047.

Van de Werfhorst, Herman G. and Nan Dirk de Graaf, 2004. 'The Sources of Political Orientations in Post-Industrial Society. Social Class and Education Revisited.' British Journal of Sociology 55(2): 211-235. doi: 10.1111/j.1468-4446.2004.00016.x.

Van Setten, Menno, Peer Scheepers, and Marcel Lubbers, 2017. 'Support for Restrictive Immigration Policies in the European Union 200213. The Impact of Economic Strain and Ethnic Threat for Vulnerable Economic Groups.' European Societies 19(4): 440-465. doi: 10.1080/14616696.2016.1268705.

Vlandas, Tim, 2020. 'The Political Consequences of Labor Market Dualization. Labor Market Status, Occupational Unemployment and Policy Preferences.' Political Science Research and Methods 8(2): 362-368. doi: $10.1017 /$ psrm.2018.42.

Vlandas, Tim and Daphne Halikiopoulou, 2022. 'Welfare State Policies and Far Right Party Support. Moderating 'Insecurity Effects' Among Different Social Groups.' West European Politics 45(1): 24-49. doi: 10.1080/01402382.2021.1886498.

Westreich, Daniel and Sander Greenland, 2013. 'The Table 2 Fallacy. Presenting and Interpreting Confounder and Modifier Coefficients.' American Journal of Epidemiology 177(4): 292-298. doi: 10.1093/aje/kws412.

Yoon, Yeosun and Heejung Chung, 2016. 'New Forms of Dualization? Labour Market Segmentation Patterns in the UK from the Late 1990's until the Post-Crisis in the Late 2000's.' Social Indicators Research 128(2): 609-631. doi: $10.1007 / \mathrm{s} 11205-015-1046-\mathrm{y}$. 


\section{Supplementary materials}

\section{Cross-national analyses}

Table A1: Sample size by country and survey round

\begin{tabular}{|c|c|c|c|c|c|c|c|c|c|c|}
\hline & \multicolumn{10}{|c|}{ ESS round } \\
\hline & 1 & 2 & 3 & 4 & 5 & 6 & 7 & 8 & 9 & Total \\
\hline Austria & 733 & 643 & 728 & 0 & 0 & 0 & 670 & 732 & 871 & 4,377 \\
\hline Belgium & 593 & 583 & 600 & 611 & 572 & 591 & 553 & 575 & 569 & 5,247 \\
\hline Denmark & 590 & 522 & 501 & 510 & 514 & 497 & 506 & 0 & 0 & 3,640 \\
\hline Finland & 719 & 689 & 627 & 739 & 0 & 691 & 600 & 573 & 534 & 5,172 \\
\hline France & 0 & 0 & 746 & 741 & 594 & 622 & 613 & 603 & 608 & 4,527 \\
\hline Germany & 900 & 826 & 842 & 851 & 962 & 900 & 978 & 955 & 734 & 7,948 \\
\hline Greece & 437 & 324 & 0 & 432 & 472 & 0 & 0 & 0 & 0 & 1,665 \\
\hline Iceland & 0 & 145 & 0 & 0 & 0 & 175 & 0 & 269 & 0 & 589 \\
\hline Ireland & 546 & 444 & 321 & 372 & 438 & 505 & 489 & 614 & 512 & 4,241 \\
\hline Italy & 302 & 364 & 0 & 0 & 0 & 219 & 0 & 595 & 556 & 2,036 \\
\hline Luxembourg & 340 & 563 & 0 & 0 & 0 & 0 & 0 & 0 & 0 & 903 \\
\hline Netherlands & 755 & 614 & 632 & 598 & 583 & 563 & 545 & 455 & 484 & 5,229 \\
\hline Norway & 826 & 678 & 677 & 619 & 599 & 643 & 520 & 563 & 524 & 5,649 \\
\hline Portugal & 424 & 498 & 567 & 493 & 450 & 462 & 307 & 210 & 273 & 3,684 \\
\hline Spain & 409 & 473 & 605 & 776 & 567 & 492 & 508 & 544 & 480 & 4,854 \\
\hline Sweden & 759 & 719 & 724 & 699 & 493 & 614 & 583 & 505 & 477 & 5,573 \\
\hline Switzerland & 664 & 746 & 581 & 611 & 488 & 495 & 505 & 514 & 524 & 5,128 \\
\hline United Kingdom & 669 & 478 & 681 & 685 & 647 & 549 & 594 & 524 & 622 & 5,449 \\
\hline Total & 9,666 & 9,309 & 8,832 & 8,737 & 7,379 & 8,018 & 7,971 & 8,231 & 7,768 & 75,911 \\
\hline
\end{tabular}

Source: European Social Survey (2002-18, ESS, 2002, 2004, 2006, 2008, 2010, 2012, 2014, 2016, 2018), own calculations. 


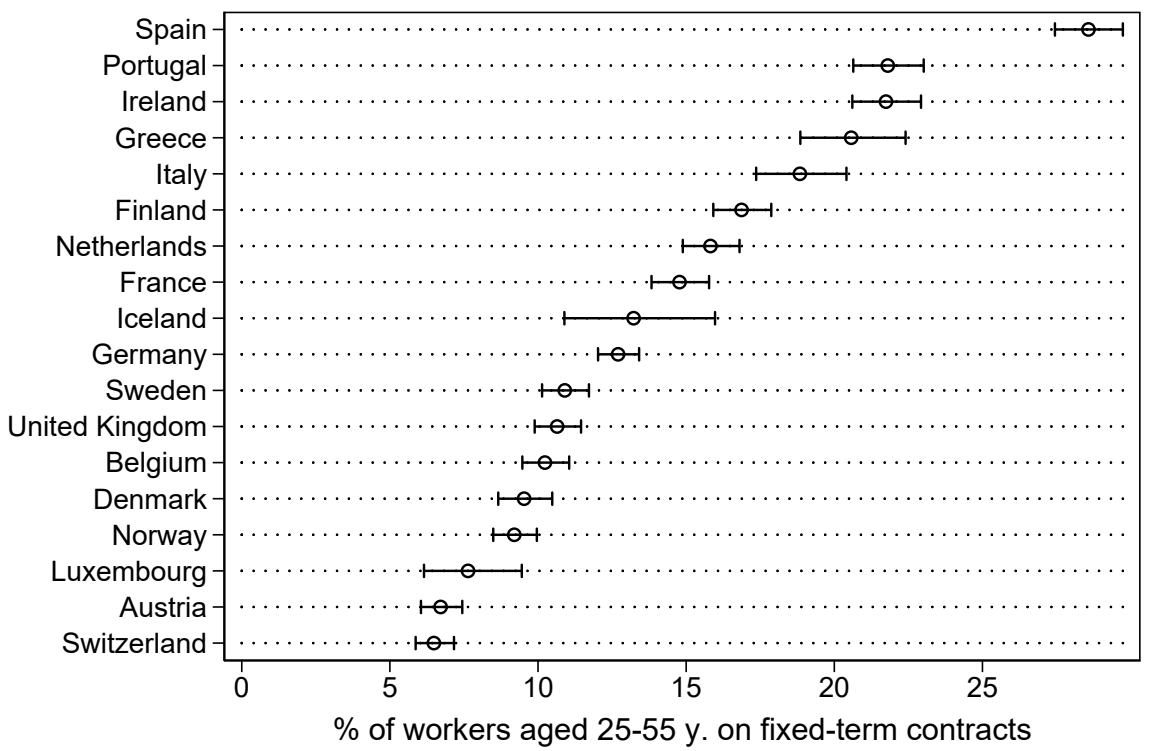

Figure A1: Percentage fixed-term workers aged 25-55 y. by country

Source: European Social Survey (2002-18, ESS, 2002, 2004, 2006, 2008, 2010, 2012, 2014, 2016, 2018), own calculations. Note: Error bars denote 95 per cent confidence intervals. 
Table A2: Anti-immigrant attitude regressed on contract type and control variables, interaction models, OLS regression, unstandardized coefficients (standard errors in parentheses).

\begin{tabular}{|c|c|c|c|c|c|c|c|c|c|}
\hline & \multicolumn{2}{|c|}{ Education } & \multicolumn{2}{|c|}{$\%$ Foreigners in industry } & \multicolumn{2}{|c|}{ \% Unemployed in industry } & \multirow{2}{*}{$\frac{\text { Three-way }}{\text { Model }}$} & \multicolumn{2}{|c|}{ EPL gap } \\
\hline & Model (1) & Model (2) & Model (1) & Model (2) & Model (1) & Model (2) & & Model (1) & Model (2) \\
\hline Fixed-term contract (Ref. permanent) & $\begin{array}{c}-0.04^{* * *} \\
(0.01)\end{array}$ & $\begin{array}{c}0.00 \\
(0.02)\end{array}$ & $\begin{array}{c}-0.04^{* * *} \\
(0.01)\end{array}$ & $\begin{array}{l}-0.03^{*} \\
(0.02)\end{array}$ & $\begin{array}{c}-0.04^{* * *} \\
(0.01)\end{array}$ & $\begin{array}{c}-0.04^{* * *} \\
(0.01)\end{array}$ & $\begin{array}{l}-0.03 \\
(0.02)\end{array}$ & $\begin{array}{c}-0.04^{* * *} \\
(0.01)\end{array}$ & $\begin{array}{c}-0.05^{* * *} \\
(0.01)\end{array}$ \\
\hline \multicolumn{10}{|l|}{ Education (Ref. low) } \\
\hline Medium & $\begin{array}{c}-0.08^{* * *} \\
(0.01)\end{array}$ & $\begin{array}{c}-0.08^{* * *} \\
(0.01)\end{array}$ & $\begin{array}{c}-0.08^{* * *} \\
(0.01)\end{array}$ & $\begin{array}{c}-0.08^{* * *} \\
(0.01)\end{array}$ & $\begin{array}{c}-0.08^{* * *} \\
(0.01)\end{array}$ & $\begin{array}{c}-0.08^{* * *} \\
(0.01)\end{array}$ & $\begin{array}{c}-0.08^{* * *} \\
(0.01)\end{array}$ & $\begin{array}{c}-0.08^{* * *} \\
(0.01)\end{array}$ & $\begin{array}{c}-0.08^{* * *} \\
(0.01)\end{array}$ \\
\hline High & $\begin{array}{c}-0.27^{* * *} \\
(0.01)\end{array}$ & $\begin{array}{c}-0.26^{* * *} \\
(0.01)\end{array}$ & $\begin{array}{c}-0.26^{* * *} \\
(0.01)\end{array}$ & $\begin{array}{c}-0.26^{* * *} \\
(0.01)\end{array}$ & $\begin{array}{c}-0.27^{* * *} \\
(0.01)\end{array}$ & $\begin{array}{c}-0.27^{* * *} \\
(0.01)\end{array}$ & $\begin{array}{c}-0.27^{* * *} \\
(0.01)\end{array}$ & $\begin{array}{c}-0.27^{* * *} \\
(0.01)\end{array}$ & $\begin{array}{c}-0.27^{* * *} \\
(0.01)\end{array}$ \\
\hline Fixed-term $\times$ Medium education & & $\begin{array}{l}-0.03 \\
(0.03)\end{array}$ & & & & & & & \\
\hline Fixed-term $\times$ High education & & $\begin{array}{c}-0.07^{* *} \\
(0.02)\end{array}$ & & & & & & & \\
\hline$\%$ foreign-born in industry & & & $\begin{array}{l}-0.00 \\
(0.00)\end{array}$ & $\begin{array}{l}-0.00 \\
(0.00)\end{array}$ & & & $\begin{array}{l}-0.00 \\
(0.00)\end{array}$ & & \\
\hline Fixed-term $\times \%$ foreign-born in industry & & & & $\begin{array}{l}-0.00 \\
(0.00)\end{array}$ & & & $\begin{array}{l}-0.00 \\
(0.00)\end{array}$ & & \\
\hline$\%$ unemployed in industry & & & & & $\begin{array}{c}-0.00^{* * *} \\
(0.00)\end{array}$ & $\begin{array}{c}-0.00^{* * *} \\
(0.00)\end{array}$ & $\begin{array}{l}-0.00 \\
(0.00)\end{array}$ & & \\
\hline Fixed-term $\times \%$ unemployed in industry & & & & & & $\begin{array}{c}0.00 \\
(0.00)\end{array}$ & $\begin{array}{l}-0.00 \\
(0.00)\end{array}$ & & \\
\hline$\%$ unemployed $\times \%$ foreign-born & & & & & & & $\begin{array}{l}-0.00 \\
(0.00)\end{array}$ & & \\
\hline Fixed-term $\times \%$ unemployed $\times \%$ foreign-born & & & & & & & $\begin{array}{l}0.00^{*} \\
(0.00)\end{array}$ & & \\
\hline EPL gap & & & & & & & & $\begin{array}{c}0.00 \\
(0.09)\end{array}$ & $\begin{array}{l}-0.00 \\
(0.09)\end{array}$ \\
\hline Fixed-term $\times$ EPL gap & & & & & & & & & $\begin{array}{l}0.02^{* *} \\
(0.01)\end{array}$ \\
\hline
\end{tabular}




\begin{tabular}{|c|c|c|c|c|c|c|c|c|c|}
\hline Female sex (Ref. male) & $\begin{array}{c}0.04^{* * *} \\
(0.01)\end{array}$ & $\begin{array}{c}0.04^{* * *} \\
(0.01)\end{array}$ & $\begin{array}{c}0.04^{* * *} \\
(0.01)\end{array}$ & $\begin{array}{c}0.04^{* * *} \\
(0.01)\end{array}$ & $\begin{array}{c}0.05^{* * *} \\
(0.01)\end{array}$ & $\begin{array}{c}0.05^{* * *} \\
(0.01)\end{array}$ & $\begin{array}{c}0.05^{* * *} \\
(0.01)\end{array}$ & $\begin{array}{c}0.04^{* * *} \\
(0.01)\end{array}$ & $\begin{array}{c}0.04^{* * *} \\
(0.01)\end{array}$ \\
\hline Foreign-born (Ref. native) & $\begin{array}{c}-0.18^{* * *} \\
(0.02)\end{array}$ & $\begin{array}{c}-0.18^{* * *} \\
(0.02)\end{array}$ & $\begin{array}{c}-0.18^{* * *} \\
(0.02)\end{array}$ & $\begin{array}{c}-0.18^{* * *} \\
(0.02)\end{array}$ & $\begin{array}{c}-0.18^{* * *} \\
(0.02)\end{array}$ & $\begin{array}{c}-0.18^{* * *} \\
(0.02)\end{array}$ & $\begin{array}{c}-0.18^{* * *} \\
(0.02)\end{array}$ & $\begin{array}{c}-0.18^{* * *} \\
(0.02)\end{array}$ & $\begin{array}{c}-0.18^{* * *} \\
(0.02)\end{array}$ \\
\hline Age & $\begin{array}{l}0.01^{* *} \\
(0.00)\end{array}$ & $\begin{array}{l}0.01^{* *} \\
(0.00)\end{array}$ & $\begin{array}{l}0.01^{* *} \\
(0.00)\end{array}$ & $\begin{array}{l}0.01^{* *} \\
(0.00)\end{array}$ & $\begin{array}{l}0.01^{*} \\
(0.00)\end{array}$ & $\begin{array}{l}0.01^{*} \\
(0.00)\end{array}$ & $\begin{array}{l}0.01^{*} \\
(0.00)\end{array}$ & $\begin{array}{l}0.01^{* *} \\
(0.00)\end{array}$ & $\begin{array}{c}0.01^{* *} \\
(0.00)\end{array}$ \\
\hline Age squared & $\begin{array}{c}0.00 \\
(0.00)\end{array}$ & $\begin{array}{c}0.00 \\
(0.00)\end{array}$ & $\begin{array}{c}0.00 \\
(0.00)\end{array}$ & $\begin{array}{c}0.00 \\
(0.00)\end{array}$ & $\begin{array}{c}0.00 \\
(0.00)\end{array}$ & $\begin{array}{c}0.00 \\
(0.00)\end{array}$ & $\begin{array}{c}0.00 \\
(0.00)\end{array}$ & $\begin{array}{c}0.00 \\
(0.00)\end{array}$ & $\begin{array}{c}0.00 \\
(0.00)\end{array}$ \\
\hline 145 Occupation FE & Yes & Yes & Yes & Yes & Yes & Yes & Yes & Yes & Yes \\
\hline Country and round FE plus interactions & Yes & Yes & Yes & Yes & Yes & Yes & Yes & Yes & Yes \\
\hline Average outcome (SD) & $2.23(0.75)$ & $2.23(0.75)$ & $2.23(0.75)$ & $2.23(0.75)$ & $2.24(0.76)$ & $2.24(0.76)$ & $2.25(0.76)$ & $2.23(0.75)$ & $2.23(0.75)$ \\
\hline$N_{\text {respondents }}\left(N_{\text {countries }}\right)$ & $75,911(18)$ & $75,911(18)$ & $73,295(18)$ & $73,295(18)$ & $70,385(18)$ & $70,385(18)$ & $69,021(18)$ & $74,767(17)$ & $74,767(17)$ \\
\hline
\end{tabular}

Source: European Social Survey (2002-18, ESS, 2002, 2004, 2006, 2008, 2010, 2012, 2014, 2016, 2018), own calculations.

Note: Standard errors are cluster-robust at the country-year level. FE: Fixed effects. SD: Standard deviation. EPL: Employment protection legislation. ${ }^{*} \mathrm{p}<0.05,{ }^{* *} \mathrm{p}<0.01, * * *$ p $<0.001$ (two-tailed). Models (2) are underlying Figure 1, Panels B to E in the main text. 


\section{Additional control variables and sample stratification}

Table A3 contains additional control variables, namely the number of working hours, marital status, household income, and area of residence, which are not strictly exogenous and might, for some assumed theoretical models, lead to biased estimates of the fixed-term contract-attitudes association. We therefore left them out of the models in the main text. However, in other assumed theoretical models, these variables may confound the fixed-term contract-attitudes association. In Table A3 we show that including these variables in the regression equations from Table 2 leads to substantively similar findings.

Table A4 stratifies the sample in different ways to gauge the robustness of findings. The first two models are stratified by sex: for both men and women, fixed-term contracts are associated with somewhat more positive attitudes towards migrants, and there are no differences between men and women in the size of the association $\left(\chi^{2}(1)=.31, p=.58\right)$.

The next three models in Table A4 compare participants in different partnership constellations: those who do not have a partner, single-earning members of couples, and members of dual-earner couples. Arguably, members of dual-earner couples are least likely to be affected by a potential job loss or job downgrading at the end of a fixed-term contract and consequently, contract status should have the smallest effect for this group. Conversely, single-earners in couples should be most financially at risk at the end of a fixed-term contract. Results show, that for all groups, workers on fixed-term contracts are less opposed to immigration than those on permanent contracts, though the relation is not significantly different for single-earners. The differences in the fixed-term contract-attitudes association between partnership status are not significant $\left(\chi^{2}(2)=3.4, p=.18\right)$.

The last column in Table A4 shows the fixed-term contract-attitudes association for the 'most likely' case, being low-educated, single-earners in working-class occupations. As job availability for this group is generally low, the possibility that migrants can take up their job comparatively high, and the financial consequences of non-renewal/not finding a new position comparatively large, one would expect a particularly pronounced relation 
between contract type and anti-immigration attitudes. However as can be seen form the Table, the coefficient is negative, small and not significantly different from zero. 
Table A3: Anti-immigrant attitude regressed on contract type and control variables, OLS regression, unstandardized coefficients including controls for marital status, working hours, household income, and area of residence (standard errors in parentheses).

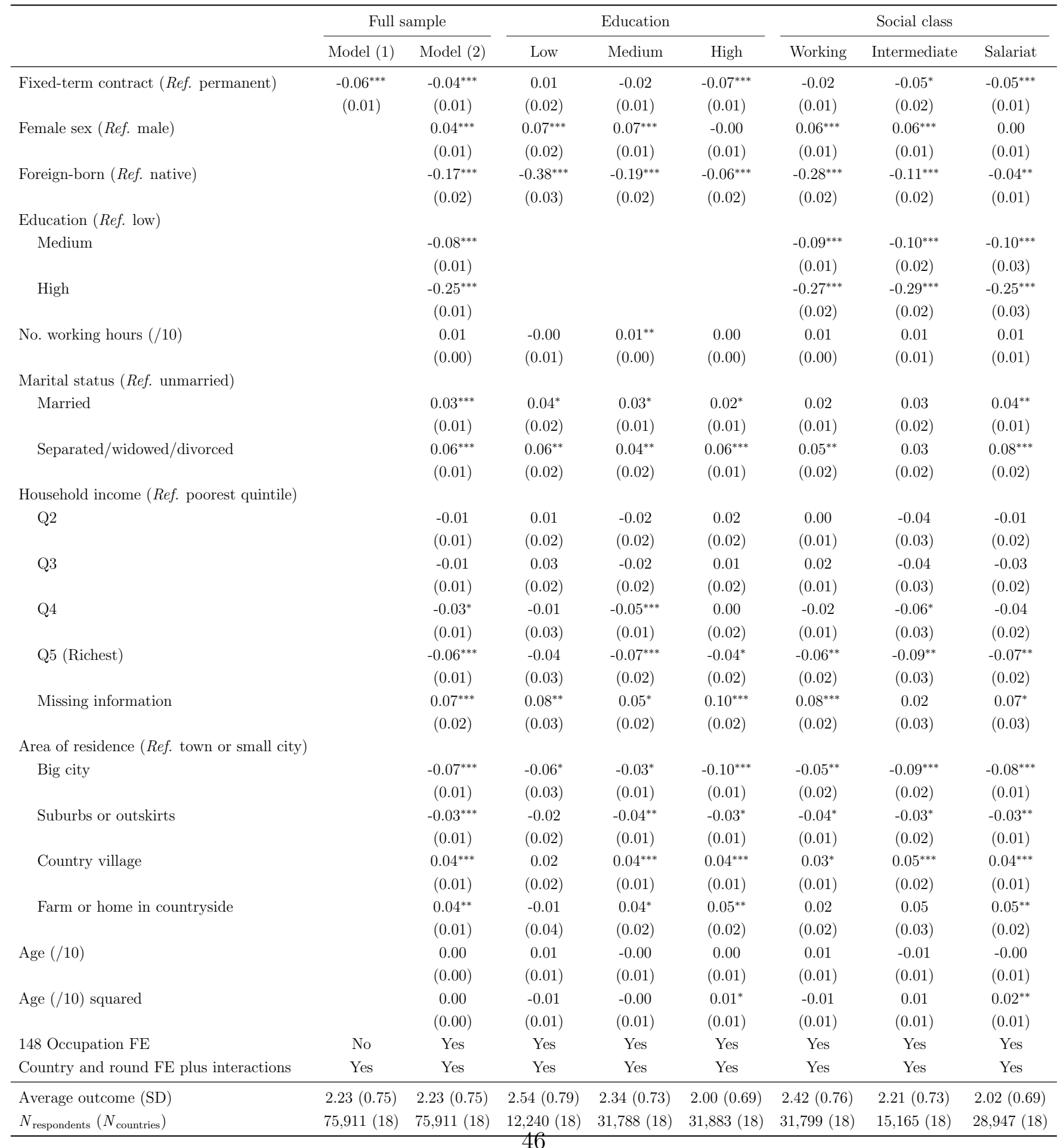

Source: European Social Survey (2002-18, ESS, 2002, 2004, 2006, 2008, 2010, 2012, 2014,

2016, 2018). Notes: Standard errors are cluster-robust at the country-year level. FE:

Fixed effects. SD: Standard deviation. ${ }^{*} \mathrm{p}<0.05,{ }^{* *} \mathrm{p}<0.01,{ }^{* * *} \mathrm{p}<0.001$ (two-tailed) 
Table A4: Anti-immigrant attitude regressed on contract type and control variables, unstandardized coefficients (standard errors in parentheses), stratified by family constellation and restricted to the 'most likely' case, i.e. lowereducated, single-earner participants in working-class occupations

\begin{tabular}{|c|c|c|c|c|c|c|}
\hline & \multicolumn{2}{|c|}{ Sex } & \multicolumn{3}{|c|}{ Partner status } & \multirow[t]{2}{*}{ Most likely case } \\
\hline & Men & Women & No partner & Single-earner & Dual-earner & \\
\hline Fixed-term contract (Ref. permanent) & $\begin{array}{c}-0.05^{* *} \\
(0.01)\end{array}$ & $\begin{array}{l}-0.03^{*} \\
(0.01)\end{array}$ & $\begin{array}{c}-0.06^{* * *} \\
(0.01)\end{array}$ & $\begin{array}{l}-0.02 \\
(0.03)\end{array}$ & $\begin{array}{l}-0.03^{*} \\
(0.01)\end{array}$ & $\begin{array}{l}-0.01 \\
(0.06)\end{array}$ \\
\hline Foreign-born (Ref. native) & $\begin{array}{c}-0.20^{* * *} \\
(0.02)\end{array}$ & $\begin{array}{c}-0.15^{* * *} \\
(0.02)\end{array}$ & $\begin{array}{c}-0.20^{* * *} \\
(0.02)\end{array}$ & $\begin{array}{c}-0.22^{* * *} \\
(0.03)\end{array}$ & $\begin{array}{c}-0.15^{* * *} \\
(0.02)\end{array}$ & $\begin{array}{c}-0.49^{* * *} \\
(0.06)\end{array}$ \\
\hline \multicolumn{7}{|l|}{ Education (Ref. low) } \\
\hline Medium & $\begin{array}{c}-0.08^{* * *} \\
(0.01)\end{array}$ & $\begin{array}{c}-0.09^{* * *} \\
(0.01)\end{array}$ & $\begin{array}{c}-0.07^{* * *} \\
(0.02)\end{array}$ & $\begin{array}{c}-0.10^{* * *} \\
(0.02)\end{array}$ & $\begin{array}{c}-0.08^{* * *} \\
(0.01)\end{array}$ & \\
\hline High & $\begin{array}{c}-0.23^{* * *} \\
(0.02)\end{array}$ & $\begin{array}{c}-0.31^{* * *} \\
(0.02)\end{array}$ & $\begin{array}{c}-0.25^{* * *} \\
(0.02)\end{array}$ & $\begin{array}{c}-0.24^{* * *} \\
(0.03)\end{array}$ & $\begin{array}{c}-0.27^{* * *} \\
(0.01)\end{array}$ & \\
\hline Age (/10) & $\begin{array}{c}0.01 \\
(0.01)\end{array}$ & $\begin{array}{l}0.02^{* *} \\
(0.01)\end{array}$ & $\begin{array}{l}0.02^{* *} \\
(0.01)\end{array}$ & $\begin{array}{c}0.01 \\
(0.01)\end{array}$ & $\begin{array}{c}0.01 \\
(0.00)\end{array}$ & $\begin{array}{c}0.03 \\
(0.02)\end{array}$ \\
\hline Age $(/ 10)$ squared & $\begin{array}{c}0.01 \\
(0.00)\end{array}$ & $\begin{array}{c}-0.00 \\
(0.00)\end{array}$ & $\begin{array}{l}-0.00 \\
(0.01)\end{array}$ & $\begin{array}{c}0.00 \\
(0.01)\end{array}$ & $\begin{array}{c}0.00 \\
(0.00)\end{array}$ & $\begin{array}{l}-0.04 \\
(0.03)\end{array}$ \\
\hline Female sex (Ref. male) & & & $\begin{array}{l}0.02^{*} \\
(0.01)\end{array}$ & $\begin{array}{c}0.09^{* * *} \\
(0.02)\end{array}$ & $\begin{array}{c}0.04^{* * *} \\
(0.01)\end{array}$ & $\begin{array}{l}0.16^{* *} \\
(0.06)\end{array}$ \\
\hline 148 Occupation FE & Yes & Yes & Yes & Yes & Yes & Yes \\
\hline Country and round FE plus interactions & Yes & Yes & Yes & Yes & Yes & Yes \\
\hline Average outcome (SD) & $2.23(0.75)$ & $2.22(0.76)$ & $2.25(0.77)$ & $2.30(0.77)$ & $2.20(0.74)$ & $2.58(0.81)$ \\
\hline$N_{\text {respondents }}\left(N_{\text {countries }}\right)$ & $38,453(18)$ & $37,458(18)$ & $22,162(18)$ & $9,322(18)$ & $44,427(18)$ & $1,940(18)$ \\
\hline
\end{tabular}

\section{Additional comparison groups on the labor market}

Analyses shown in the main text compare those on a fixed-term contract to those with a permanent contract. In this section, we compare these key groups with other groups on the labor market, namely those without a work contract, the unemployed - distinguishing by prior contract status-, and the self-employed.

Workers without a contract are more opposed to immigration than those on a fixed-term or a permanent contract, although the difference with the latter is not significant. Workers without a contract are a heterogeneous group consisting of workers in the informal economy, helping family members, and civil servants with high job security. Consequently, the presumed exposure to labor market competition with immigrants varies within the no-contract group, making it difficult to interpret this result as evidence for or against ethnic competition theory. 
As shown in Figure A2, the unemployed are more opposed to immigration than those on fixed-term or permanent contracts. This finding is in line with the expectations of ethnic competition theory. Interestingly, the pattern across (prior) contract status - permanent, fixed or none - is similar to that of those currently employed. The self-employed are also more opposed to immigrants than those on fixed-term contracts. Similar to workers without a contract, this group is heterogeneous in its exposure to competition with immigrants, making it difficult to interpret this difference against the backdrop of ethnic competition theory.

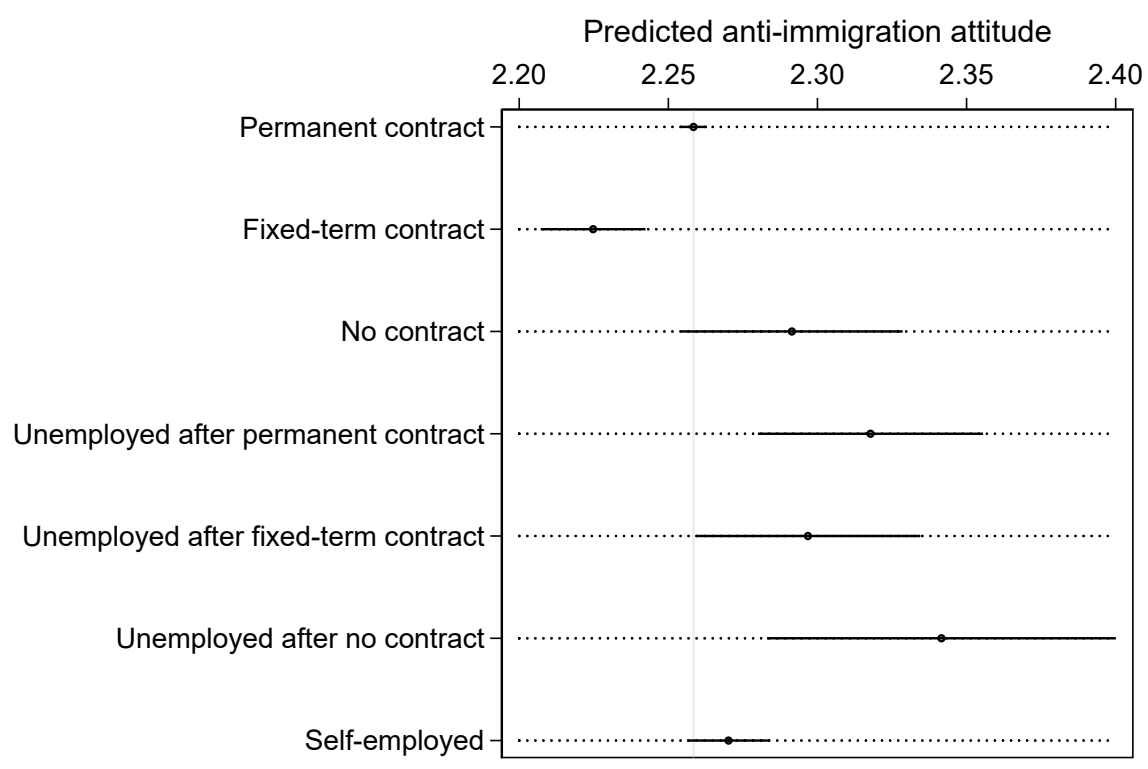

Figure A2: Differences in anti-immigration attitudes between labor market groups

Source: European Social Survey (2002-18, ESS, 2002, 2004, 2006, 2008, 2010, 2012, 2014, 2016, 2018), own calculations. Notes: Vertical gray line indicates predicted antiimmigration attitude of those with a permanent contract. Error spikes denote 95 per cent confidence intervals. Based on a model accounting for all control variables of Model (2) of Table 2 . 


\section{No changes in the fixed-term contract-anti-immigration attitude association over time}

One might assume that there are changes in the fixed-term contract-antiimmigration attitude association over time: a fixed-term contract in the early 2000's might produce a very different effect than in the 2010's, since unemployment rates declined substantially over this period. To test this, we re-estimated Model (2) of Table 2 with an interaction between survey round and fixed-term contract. Results are shown in Figure A3, which reveals that there is no difference in the size of the gap in anti-immigrant attitude between fixed-term and permanent contracts.

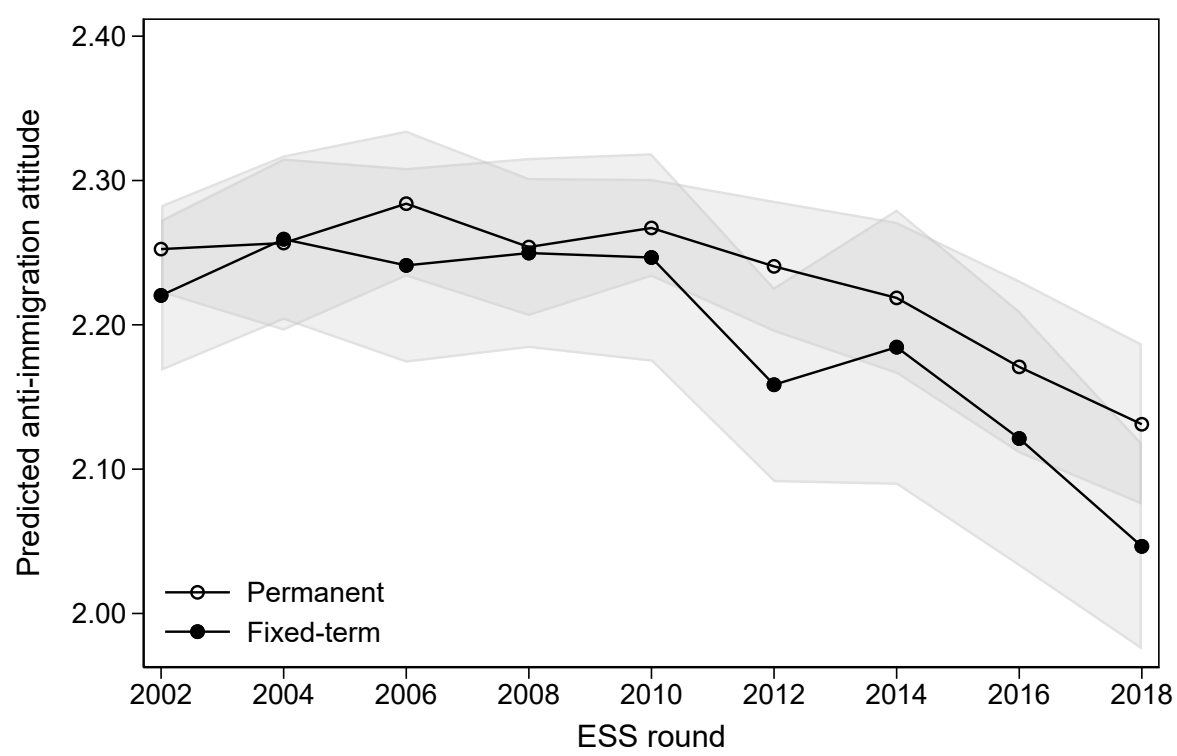

Figure A3: Fixed-term gap in anti-immigration attitude is relatively constant over time

Source: European Social Survey (2002-18, ESS, 2002, 2004, 2006, 2008, 2010, 2012, 2014, 2016, 2018), own calculations. Note: Error bands denote 95 per cent confidence intervals.

\section{Gender and anti-immigration attitude in the ESS}

While women are generally known to have a lower anti-immigration attitude than men, Table 2 shows an unexpected positive coefficient for the gender 
variable, suggesting that women have a stronger anti-immigration attitude than men. Generally, it can be misleading to interpret the coefficients of control variables in multivariable models, as they will be biased estimates of the causal effects (also known as the 'Table 2 fallacy,' Westreich and Greenland, 2013).

To demonstrate that the direction of the gender association is not because of a coding error, Figure A4 shows the size and direction of the association between gender and anti-immigration attitudes for different model specifications. Model M1 shows the expected gender difference: when controlling only for country and survey round, women have a lower anti-immigration attitude than men. M2 shows that this is by virtue of women's generally higher education: When comparing men and women of the same educational level, we find no gender differences in anti-immigration attitude. This remains true when we add the remaining control variables from Table 2 to the equation (M3). Once we start comparing men and women in the same occupational group (M4), we see that women have a higher anti-immigrant attitude than men in the same occupational group. This holds true irrespective of the control variables (M5). 


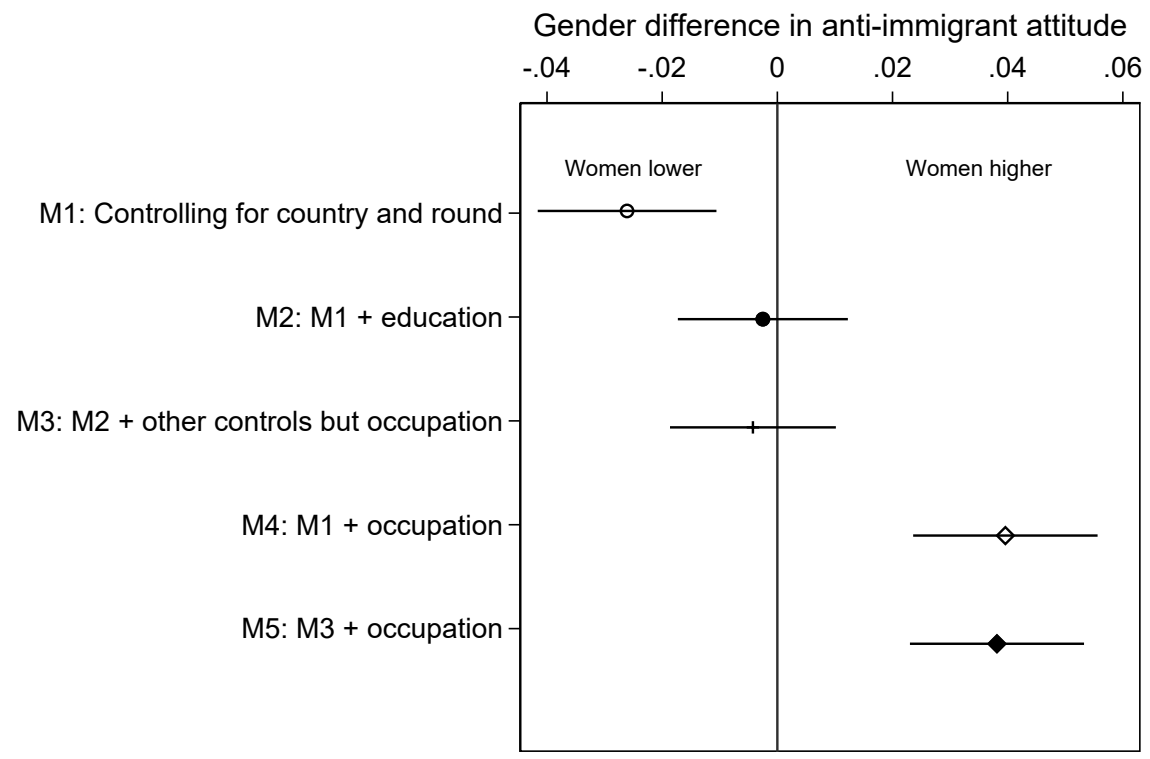

Figure A4: Gender coefficient for anti-immigration attitude in five different model specifications

Source: European Social Survey (2002-18, ESS, 2002, 2004, 2006, 2008, 2010, 2012, 2014, 2016, 2018), own calculations. Note: Error bars denote 95 per cent confidence intervals. 


\section{Longitudinal analyses}

Table A5: Concern about immigration and contract type, interactions with percentage foreigners in industry, fixed-effects LPM panel regression models (robust standard errors in parentheses)

\begin{tabular}{|c|c|c|c|c|}
\hline & \multicolumn{2}{|c|}{ Contract type } & \multicolumn{2}{|c|}{ Transition type } \\
\hline & (1) & $(2)$ & $(3)$ & $(4)$ \\
\hline & $\mathrm{FE}$ & $\mathrm{FE}$ & $\mathrm{FE}$ & $\mathrm{FE}$ \\
\hline Fixed-term contract (Ref. permanent) & $\begin{array}{c}0.005 \\
(0.005)\end{array}$ & $\begin{array}{c}0.010 \\
(0.010)\end{array}$ & & \\
\hline Percentage foreigners in industry & $\begin{array}{c}0.001 \\
(0.000)\end{array}$ & $\begin{array}{c}0.001 \\
(0.000)\end{array}$ & $\begin{array}{l}0.001^{*} \\
(0.000)\end{array}$ & $\begin{array}{l}0.001^{*} \\
(0.000)\end{array}$ \\
\hline Fixed-term $\times$ Percentage foreigners in industry & & $\begin{array}{l}-0.000 \\
(0.001)\end{array}$ & & \\
\hline \multicolumn{5}{|l|}{ Contract type transitions (Ref. permanent $\rightarrow$ permanent) } \\
\hline Permanent $\rightarrow$ fixed & & & $\begin{array}{c}0.001 \\
(0.008)\end{array}$ & $\begin{array}{c}0.004 \\
(0.016)\end{array}$ \\
\hline Fixed $\rightarrow$ permanent & & & $\begin{array}{l}-0.007 \\
(0.007)\end{array}$ & $\begin{array}{c}0.000 \\
(0.012)\end{array}$ \\
\hline Fixed $\rightarrow$ fixed & & & $\begin{array}{l}-0.001 \\
(0.008)\end{array}$ & $\begin{array}{c}0.009 \\
(0.014)\end{array}$ \\
\hline \multicolumn{5}{|l|}{ Interactions } \\
\hline Permanent $\rightarrow$ fixed $\times$ Percentage foreigners in industry & & & & $\begin{array}{l}-0.000 \\
(0.001)\end{array}$ \\
\hline Fixed $\rightarrow$ permanent $\times$ Percentage foreigners in industry & & & & $\begin{array}{l}-0.001 \\
(0.001)\end{array}$ \\
\hline Fixed $\rightarrow$ fixed $\times$ Percentage foreigners in industry & & & & $\begin{array}{l}-0.001 \\
(0.001)\end{array}$ \\
\hline Age & $\begin{array}{c}-0.007^{* *} \\
(0.003)\end{array}$ & $\begin{array}{c}-0.007^{* *} \\
(0.003)\end{array}$ & $\begin{array}{c}-0.006^{*} \\
(0.003)\end{array}$ & $\begin{array}{l}-0.006^{*} \\
(0.003)\end{array}$ \\
\hline Age squared & $\begin{array}{c}0.000^{* *} \\
(0.000)\end{array}$ & $\begin{array}{c}0.000^{* *} \\
(0.000)\end{array}$ & $\begin{array}{c}0.000^{* *} \\
(0.000)\end{array}$ & $\begin{array}{c}0.000^{* *} \\
(0.000)\end{array}$ \\
\hline \multicolumn{5}{|l|}{ Education (Ref. low) } \\
\hline Medium & $\begin{array}{c}0.030 \\
(0.018)\end{array}$ & $\begin{array}{c}0.030 \\
(0.018)\end{array}$ & $\begin{array}{l}-0.021 \\
(0.045)\end{array}$ & $\begin{array}{l}-0.021 \\
(0.045)\end{array}$ \\
\hline High & $\begin{array}{c}0.036 \\
(0.020)\end{array}$ & $\begin{array}{c}0.036 \\
(0.020)\end{array}$ & $\begin{array}{l}-0.024 \\
(0.046)\end{array}$ & $\begin{array}{l}-0.024 \\
(0.046)\end{array}$ \\
\hline Intercept & $\begin{array}{c}0.362^{* * *} \\
(0.068)\end{array}$ & $\begin{array}{c}0.359^{* * *} \\
(0.068)\end{array}$ & $\begin{array}{c}0.341^{* * *} \\
(0.083)\end{array}$ & $\begin{array}{c}0.334^{* * *} \\
(0.083)\end{array}$ \\
\hline
\end{tabular}




\begin{tabular}{lcccc}
\hline 110 Occupation FE included & Yes & Yes & Yes & Yes \\
Year FE included & Yes & Yes & Yes & Yes \\
\hline$N_{\text {observations }}$ & 126,334 & 126,334 & 104,405 & 104,405 \\
$N_{\text {individuals }}$ & 28,443 & 28,443 & 22,346 & 22,346 \\
\hline
\end{tabular}

Source: German Socio-Economic Panel (GSOEP, 1999-2015, Schupp et al., 2017), own calculations. Notes: FE: Fixed effects. ${ }^{*} \mathrm{p}<0.05,{ }^{* *} \mathrm{p}<0.01,{ }^{* * *} \mathrm{p}<0.001$ (two-tailed). All models include year fixed effects (not shown). Predictions based on Models (2) and (4) shown in Figure 4 in the main text. 
Table A6: Concern about immigration and contract type, interactions with percentage unemployed in industry, fixed-effects LPM panel regression models (robust standard errors in parentheses)

\begin{tabular}{|c|c|c|c|c|}
\hline & \multicolumn{2}{|c|}{ Contract type } & \multicolumn{2}{|c|}{ Transition type } \\
\hline & $(1)$ & $(2)$ & $(3)$ & (4) \\
\hline & $\mathrm{FE}$ & $\mathrm{FE}$ & $\mathrm{FE}$ & $\mathrm{FE}$ \\
\hline Fixed-term contract (Ref. permanent) & $\begin{array}{c}0.005 \\
(0.005)\end{array}$ & $\begin{array}{c}0.006 \\
(0.006)\end{array}$ & & \\
\hline Percentage unemployed in industry & $\begin{array}{l}-0.000 \\
(0.001)\end{array}$ & $\begin{array}{l}-0.000 \\
(0.001)\end{array}$ & $\begin{array}{l}-0.000 \\
(0.001)\end{array}$ & $\begin{array}{c}0.000 \\
(0.001)\end{array}$ \\
\hline Fixed-term $\times$ Percentage unemployed in industry & & $\begin{array}{l}-0.001 \\
(0.002)\end{array}$ & & \\
\hline \multicolumn{5}{|l|}{ Contract type transitions (Ref. permanent $\rightarrow$ permanent) } \\
\hline Permanent $\rightarrow$ fixed & & & $\begin{array}{c}0.001 \\
(0.008)\end{array}$ & $\begin{array}{l}-0.001 \\
(0.011)\end{array}$ \\
\hline Fixed $\rightarrow$ permanent & & & $\begin{array}{l}-0.007 \\
(0.007)\end{array}$ & $\begin{array}{l}-0.005 \\
(0.009)\end{array}$ \\
\hline Fixed $\rightarrow$ fixed & & & $\begin{array}{l}-0.001 \\
(0.008)\end{array}$ & $\begin{array}{c}0.002 \\
(0.009)\end{array}$ \\
\hline \multicolumn{5}{|l|}{ Interactions } \\
\hline Permanent $\rightarrow$ fixed $\times \%$ unemployed in industry & & & & $\begin{array}{c}0.001 \\
(0.005)\end{array}$ \\
\hline Fixed $\rightarrow$ permanent $\times \%$ unemployed in industry & & & & $\begin{array}{l}-0.002 \\
(0.004)\end{array}$ \\
\hline Fixed $\rightarrow$ fixed $\times \%$ unemployed in industry & & & & $\begin{array}{l}-0.002 \\
(0.003)\end{array}$ \\
\hline Age & $\begin{array}{c}-0.007^{*} \\
(0.003)\end{array}$ & $\begin{array}{l}-0.007^{*} \\
(0.003)\end{array}$ & $\begin{array}{r}-0.006^{*} \\
(0.003)\end{array}$ & $\begin{array}{l}-0.006^{*} \\
(0.003)\end{array}$ \\
\hline Age squared & $\begin{array}{c}0.000^{* *} \\
(0.000)\end{array}$ & $\begin{array}{c}0.000^{* *} \\
(0.000)\end{array}$ & $\begin{array}{c}0.000^{* *} \\
(0.000)\end{array}$ & $\begin{array}{l}0.000^{* *} \\
(0.000)\end{array}$ \\
\hline \multicolumn{5}{|l|}{ Education (Ref. low) } \\
\hline Medium & $\begin{array}{c}0.030 \\
(0.018)\end{array}$ & $\begin{array}{c}0.030 \\
(0.018)\end{array}$ & $\begin{array}{l}-0.022 \\
(0.045)\end{array}$ & $\begin{array}{l}-0.022 \\
(0.045)\end{array}$ \\
\hline High & $\begin{array}{c}0.036 \\
(0.020)\end{array}$ & $\begin{array}{c}0.036 \\
(0.020)\end{array}$ & $\begin{array}{l}-0.025 \\
(0.046)\end{array}$ & $\begin{array}{l}-0.025 \\
(0.046)\end{array}$ \\
\hline Intercept & $\begin{array}{r}0.363^{* * *} \\
(0.068)\end{array}$ & $\begin{array}{c}0.362^{* * *} \\
(0.068)\end{array}$ & $\begin{array}{c}0.339^{* * *} \\
(0.083)\end{array}$ & $\begin{array}{c}0.338^{* * *} \\
(0.083)\end{array}$ \\
\hline 110 Occupation FE included & Yes & Yes & Yes & Yes \\
\hline
\end{tabular}




\begin{tabular}{lcccc}
\hline Year FE included & Yes & Yes & Yes & Yes \\
\hline$N_{\text {observations }}$ & 126,334 & 126,334 & 104,405 & 104,405 \\
$N_{\text {individuals }}$ & 28,443 & 28,443 & 22,346 & 22,346 \\
\hline
\end{tabular}

Source: German Socio-Economic Panel (GSOEP, 1999-2015, Schupp et al., 2017), own calculations. Notes: FE: Fixed effects. ${ }^{*} \mathrm{p}<0.05,{ }^{* *} \mathrm{p}<0.01,{ }^{* * *} \mathrm{p}<0.001$ (two-tailed). All models include year fixed effects (not shown). Predictions based on Models (2) and (4) shown in Figure 4 in the main text. 


\section{Additional control variables}

Table A7: Concern about immigration and contract type, random- and fixedeffects LPM panel regression models (robust standard errors in parentheses), additional controls for working hours, household income, and marital status

\begin{tabular}{|c|c|c|c|c|c|c|}
\hline & \multicolumn{4}{|c|}{ Contract type } & \multicolumn{2}{|c|}{ Transition type } \\
\hline & $\mathrm{RE}$ & $\mathrm{RE}$ & $\mathrm{FE}$ & $\mathrm{FE}$ & $\mathrm{FE}$ & $\mathrm{FE}$ \\
\hline Fixed-term contract (Ref. permanent) & $\begin{array}{l}-0.000 \\
(0.004)\end{array}$ & $\begin{array}{l}0.010^{*} \\
(0.004)\end{array}$ & $\begin{array}{c}0.007 \\
(0.005)\end{array}$ & $\begin{array}{c}0.008 \\
(0.005)\end{array}$ & & \\
\hline \multicolumn{7}{|c|}{ Contract type transitions (Ref. permanent $\rightarrow$ permanent) } \\
\hline Permanent $\rightarrow$ fixed & & & & & $\begin{array}{c}0.007 \\
(0.008)\end{array}$ & $\begin{array}{c}0.007 \\
(0.008)\end{array}$ \\
\hline Fixed $\rightarrow$ permanent & & & & & $\begin{array}{l}-0.005 \\
(0.006)\end{array}$ & $\begin{array}{l}-0.006 \\
(0.006)\end{array}$ \\
\hline Fixed $\rightarrow$ fixed & & & & & $\begin{array}{c}0.001 \\
(0.008)\end{array}$ & $\begin{array}{l}-0.000 \\
(0.008)\end{array}$ \\
\hline Female (Ref. male) & & $\begin{array}{l}0.010^{*} \\
(0.005)\end{array}$ & & & & \\
\hline Foreign-born (Ref. native) & & $\begin{array}{c}-0.121^{* * *} \\
(0.005)\end{array}$ & & & & \\
\hline Age & & $\begin{array}{l}-0.000 \\
(0.002)\end{array}$ & & $\begin{array}{l}-0.005 \\
(0.003)\end{array}$ & & $\begin{array}{l}-0.004 \\
(0.003)\end{array}$ \\
\hline Age squared & & $\begin{array}{c}0.000 \\
(0.000)\end{array}$ & & $\begin{array}{l}0.000^{*} \\
(0.000)\end{array}$ & & $\begin{array}{l}0.000^{*} \\
(0.000)\end{array}$ \\
\hline No. working hours & & $\begin{array}{c}0.012^{* * *} \\
(0.001)\end{array}$ & & $\begin{array}{l}0.006^{* *} \\
(0.002)\end{array}$ & & $\begin{array}{c}0.007^{* * *} \\
(0.002)\end{array}$ \\
\hline \multicolumn{7}{|l|}{ Household income (Ref. poorest quintile) } \\
\hline Q2 & & $\begin{array}{l}-0.005 \\
(0.006)\end{array}$ & & $\begin{array}{l}-0.006 \\
(0.007)\end{array}$ & & $\begin{array}{l}-0.008 \\
(0.008)\end{array}$ \\
\hline Q3 & & $\begin{array}{c}0.003 \\
(0.006)\end{array}$ & & $\begin{array}{c}0.006 \\
(0.008)\end{array}$ & & $\begin{array}{c}0.003 \\
(0.009)\end{array}$ \\
\hline Q4 & & $\begin{array}{c}-0.006 \\
(0.006)\end{array}$ & & $\begin{array}{c}0.010 \\
(0.008)\end{array}$ & & $\begin{array}{c}0.009 \\
(0.009)\end{array}$ \\
\hline Q5 (richest) & & $\begin{array}{c}-0.029^{* * *} \\
(0.007)\end{array}$ & & $\begin{array}{c}0.005 \\
(0.008)\end{array}$ & & $\begin{array}{c}0.004 \\
(0.009)\end{array}$ \\
\hline Missing information & & $\begin{array}{c}0.009 \\
(0.008)\end{array}$ & & $\begin{array}{c}0.010 \\
(0.010)\end{array}$ & & $\begin{array}{c}0.010 \\
(0.011)\end{array}$ \\
\hline \multicolumn{7}{|l|}{ Education (Ref. low) } \\
\hline Medium & & $\begin{array}{c}-0.029^{* * *} \\
(0.007)\end{array}$ & & $\begin{array}{c}0.030 \\
(0.017)\end{array}$ & & $\begin{array}{l}-0.033 \\
(0.042)\end{array}$ \\
\hline High & & $\begin{array}{c}-0.115^{* * *} \\
(0.008)\end{array}$ & & $\begin{array}{c}0.036 \\
(0.020)\end{array}$ & & $\begin{array}{l}-0.035 \\
(0.042)\end{array}$ \\
\hline \multicolumn{7}{|l|}{ Marital status (Ref. unmarried) } \\
\hline Married & & $\begin{array}{c}0.005 \\
(0.005)\end{array}$ & & $\begin{array}{l}-0.018^{*} \\
(0.008)\end{array}$ & & $\begin{array}{l}-0.021^{*} \\
(0.009)\end{array}$ \\
\hline Divorced/widowed & & $\begin{array}{c}0.010 \\
(0.007)\end{array}$ & & $\begin{array}{l}-0.020 \\
(0.012)\end{array}$ & & $\begin{array}{l}-0.024 \\
(0.013)\end{array}$ \\
\hline Intercept & $\begin{array}{c}0.317^{* * *} \\
(0.006)\end{array}$ & $\begin{array}{c}0.326^{* * *} \\
(0.046)\end{array}$ & $\begin{array}{c}0.301^{* * *} \\
(0.006)\end{array}$ & $\begin{array}{c}0.284^{* * *} \\
(0.068)\end{array}$ & $\begin{array}{c}0.272^{* * *} \\
(0.006)\end{array}$ & $\begin{array}{l}0.268^{* *} \\
(0.082)\end{array}$ \\
\hline 110 Occupation FE & No & Yes & No & Yes & No & Yes \\
\hline Year FE included & Yes56 & Yes & Yes & Yes & Yes & Yes \\
\hline$N_{\text {observations }}$ & 130,498 & 130,498 & 130,498 & 130,498 & 107,985 & 107,985 \\
\hline$N_{\text {individuals }}$ & 29,576 & 29,576 & 29,576 & 29,576 & 23,411 & 23,411 \\
\hline
\end{tabular}




\section{Additional comparison groups on the labor market}

Analyses shown in the main text compare those on a fixed-term contract to those with a permanent contract. Here, we compare those key groups with other groups on the labor market, namely those without a work contract, the unemployed, and the self-employed. Those without a work contract are a heterogeneous group consisting of workers in the informal economy, helping family members, civil servants with very high job security, and workers who are protected by the relatively stringent labor legislation in Germany.

Figure A5 shows that workers without a contract are slightly more concerned about immigration than those on permanent contracts, yet this difference is not significantly different from zero. Self-employed are very slightly less opposed than those on permanent contracts, but the difference is again not significant. As both workers without contracts and the self-employed are very heterogenous groups, it is unclear whether they on the whole face more or less competition than people on fixed-term and permanent contracts. This raises doubt about whether whether the coefficients vs. permanent contract for these groups should be interpreted as support for ethnic competition theory or not. 


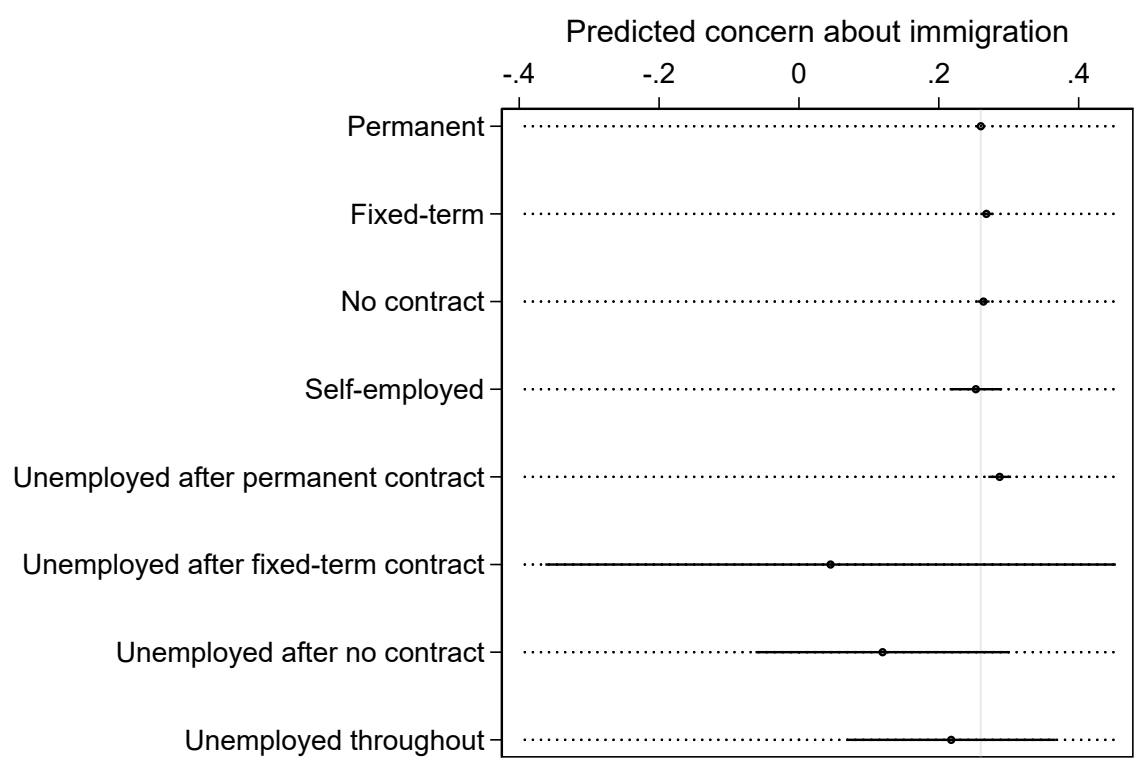

Figure A5: Differences in concern about immigration between labor market groups

Source: German Socio-Economic Panel (GSOEP, 1999-2015, Schupp et al., 2017), own calculations. Notes: Vertical gray line indicates the predicted concern about immigration for workers with permanent contracts. Error spikes denote 95 per cent confidence intervals. Based on a fixed effects model accounting for all control variables of Model (2) of Table 4. 